Article

\title{
An Efficient One-Pot Catalyzed Synthesis of 2,4-Disubstituted 5-Nitroimidazoles Displaying Antiparasitic and Antibacterial Activities
}

\author{
Fanny Mathias ${ }^{1}$, Youssef Kabri ${ }^{1}$, Liliane Okdah ${ }^{2}$, Carole Di Giorgio ${ }^{3}$, Jean-Marc Rolain ${ }^{2}$, \\ Cédric Spitz ${ }^{1}$, Maxime D. Crozet ${ }^{1}$ and Patrice Vanelle ${ }^{1, *}$ \\ 1 Aix Marseille University, Institut de Chimie Radicalaire ICR, UMR CNRS 7273, Laboratoire de \\ Pharmaco-Chimie Radicalaire, Faculté de Pharmacie, 27 Boulevard Jean Moulin—CS 30064, \\ 13385 Marseille CEDEX 05, France; fanny.mathias@laposte.net (F.M.); youssef.kabri@univ-amu.fr (Y.K.); \\ cedric.spitz@univ-amu.fr (C.S.); maxime.crozet@univ-amu.fr (M.D.C.) \\ 2 IHU Méditerranée Infection, Aix Marseille University, Unité de Recherche sur les Maladies Infectieuses et \\ Tropicales Emergentes, URMITE UMR 63, CNRS 7278, IRD 198, Inserm 1095, Faculté de Médecine de la \\ Timone, 19-21 Boulevard Jean Moulin, 13005 Marseille, France; liliane.okdah@hotmail.com (L.O.); \\ jean-marc.rolain@univ-amu.fr (J.-M.R.) \\ 3 Aix Marseille University, CNRS, IRD, Avignon Université, IMBE UMR 7263, Laboratoire de Mutagénèse \\ Environnementale, 13385 Marseille, France; carole.di-giorgio@univ-amu.fr \\ * Correspondence: patrice.vanelle@univ-amu.fr; Tel.: +33-4-9183-5580
}

Received: 20 July 2017; Accepted: 29 July 2017; Published: 3 August 2017

\begin{abstract}
A one-pot regioselective bis-Suzuki-Miyaura or Suzuki-Miyaura/Sonogashira reaction on 2,4-dibromo-1-methyl-5-nitro- $1 \mathrm{H}$-imidazole under microwave heating was developed. This method is applicable to a wide range of (hetero)arylboronic acids and terminal alkynes. Additionally, this approach provides a simple and efficient way to synthesize 2,4-disubstituted 5-nitroimidazole derivatives with antibacterial and antiparasitic properties.
\end{abstract}

Keywords: 5-nitroimidazole; Suzuki-Miyaura/Sonogashira; regioselectivity; microwave; antiparasitic; antibacterial

\section{Introduction}

Nitroimidazole drugs show a wide range of activities against parasites and anaerobic bacteria. These activities vary according to the nature of the substituents and the position of the nitro group [1-7]. Metronidazole (mtz) appears on the WHO Model List of Essential Medicines and is today the most commonly used 5-nitroimidazole compound worldwide.

5-Nitroimidazoles are prodrugs which need to be activated by reduction of their nitro group. Reduced metronidazole forms covalent bonds to DNA macromolecules, leading to the loss of helical structure and irreversible breaking [8]. The reduction of these compounds involves several anaerobic enzymatic pathways such as ferredoxin oxidoreductase [9], nitroreductase [10] and thioredoxin reductase [11].

Resistance to metronidazole has emerged, but despite studies on Trichomonas vaginalis [9,12-15], Giardia intestinalis [16-18], and anaerobic bacteria [19-23], the mechanism is not yet fully understood. Such resistance leads physicians to use higher doses of metronidazole and longer courses of treatment to improve activity [24].

However, higher doses and longer regimens may promote side effects and decrease compliance. Although the most common side effects of metronidazole treatment are mild (headache, vertigo, nausea, a metallic taste in the mouth and an Antabuse-like effect with alcohol) [25], other more serious adverse effects have been documented, such as mutagenicity on bacteria [26-31] and carcinogenicity on 
mice and rats [32]. Moreover, in recent decades, an increasing number of anaerobic bacterial pathogens have been observed to cause severe diarrhea and enterocolitis [33-36].

Therefore, there is an ongoing search for alternative 5-nitroimidazoles effective on anaerobic-resistant strains without serious adverse effects [37-48]. Following the work of Walsh et al. in 1987 [49], we focused our research on pharmacomodulation of the 2- and 4-positions of the 5-nitroimidazole scaffold [50].

Palladium-catalyzed reactions, particularly Suzuki-Miyaura cross-coupling, are widely applied in the synthesis of bioactive complex molecules, offering mild reaction conditions and compatibility with a broad range of functional groups [51,52]. Moreover, some Suzuki-Miyaura cross-coupling conditions allow regioselective cross-coupling on polyhalogenated heterocycles [53,54], leaving a halogenated $\alpha$ position unchanged and able to react in a second step. This enables a wide range of compounds with the same starting material.

The regioselectivity in the Suzuki-Miyaura reaction is driven by the electrophilic properties of the halogenated carbon. During the oxidative addition step, the palladium catalyst which is a nucleophilic species, specifically links the most electrophilic halogenated carbon [53-55]. The nitro group, essential for medicinal properties, can also act as a chemical directing group during synthesis [56]. Thus, the nitro group in position 5 can significantly increase the electrophilic properties of the $C-4$, making this position the most reactive toward cross-coupling reactions, although on the naked imidazole ring, the C-2 position was described as the most reactive [57,58].

As part of our research program centered on the design and synthesis of novel 5-nitroimidazole compounds $[40,43,48,50,59,60]$, we decided to exploit this particular reactivity of the 5-nitroimidazole series toward cross-coupling reactions, seeking a rapid and versatile pathway for the synthesis of 2,4-disubstitued 5-nitroimidazole derivatives. Therefore, we report herein a regioselective Suzuki-Miyaura cross-coupling between 2,4-dibromo-1-methyl-5-nitro- $1 \mathrm{H}$-imidazole (2) and aryl or heteroarylboronic acids resulting in the formation of 2-bromo-4-substituted-1-methyl-5-nitroimidazoles which can then undergo a second (Suzuki-Miyaura or Sonogashira) cross-coupling reaction to obtain 2,4-disubstituted 5-nitroimidazoles during a sequential one-pot process.

Finally, the antiparasitic activity of the obtained 5-nitroimidazole derivatives was assessed against T. vaginalis and anaerobic bacteria of the genus Clostridium and Bacillus.

\section{Results}

\subsection{Chemistry}

The synthesis of 2,4-dibromo-1-methyl-5-nitro- $1 H$-imidazole (2) was realized from the commercial product 4(5)-nitroimidazole in two sequential steps, as shown in Scheme 1. The first step consisted of bromination with elemental bromine in water and in the presence of sodium hydrogen carbonate, according to Pedada et al. [61]. The 2,4(5)-dibromo-5(4)-nitroimidazole mixture was then alkylated by dimethyl sulphate (DMS) in DMF leading to two isomeric products $\mathbf{1}$ and $\mathbf{2}$ in $71 \%$ overall yield.

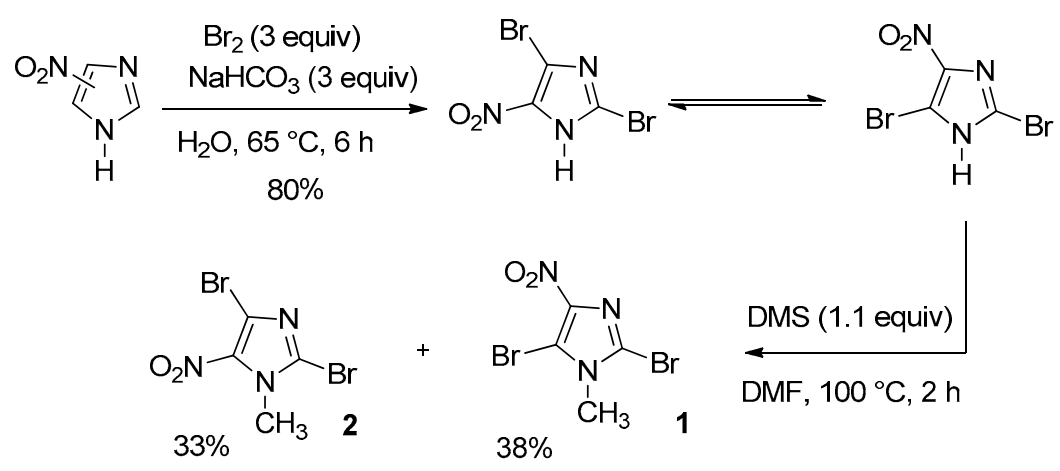

Scheme 1. Synthesis of 2,4-dibromo-1-methyl-5-nitro-1H-imidazole (2). 
Our particular aim in exploring the reactivity of 2,4-dibromo-1-methyl-5-nitro- $1 H$-imidazole (2) in Suzuki-Miyaura reactions was to test the regioselectivity of this type of reaction toward the halogenated positions C-2 and C-4.

We began our study by optimizing the regioselective coupling reaction of compound 2 with phenylboronic acid (1.1 equiv.) in the presence of $\mathrm{Pd}\left(\mathrm{PPh}_{3}\right)_{4}\left(0.04\right.$ equiv.) as catalyst, $\mathrm{Na}_{2} \mathrm{CO}_{3}$ (3 equiv.) as base, in a mixture of DME/EtOH/ $\mathrm{H}_{2} \mathrm{O}(3 / 1 / 1)$ as solvent. First, the reaction was performed at room temperature, and after $1.5 \mathrm{~h}$, no conversion of compound 2 was observed (Table 1 , entry 1 ). When the temperature was increased to $60{ }^{\circ} \mathrm{C}$, after $48 \mathrm{~h}$ of reaction, a mixture of compounds $2 / 3 \mathrm{a} / 4 / 5$ was observed with both low conversion and selectivity (LC/MS ratio $25 / 28 / 26 / 21 \%$, respectively) (Table 1, entry 2). In these conditions, the reactivity of positions C-2 and C-4 was similar. The use of microwave irradiation at $80^{\circ} \mathrm{C}$ for $1 \mathrm{~h}$ (Table 1, entry 4) allowed better conversion of compound 2 in the Suzuki-Miyaura reaction, with lower selectivity and improved yield of the dicoupled compound $\mathbf{5}$. Next, we examined the influence of other palladium sources such as $\mathrm{PdCl}_{2}\left(\mathrm{PPh}_{3}\right)_{2}, \mathrm{Pd}(\mathrm{DPPF}) \mathrm{Cl}_{2}$ and $\mathrm{Pd}(\mathrm{OAc})_{2}$. With $\mathrm{PdCl}_{2}\left(\mathrm{PPh}_{3}\right)_{2}$ and $\mathrm{Pd}(\mathrm{DPPF}) \mathrm{Cl}_{2}$, low conversion was observed and there was no improvement in terms of selectivity (Table 1 , entries 5 and 6). To our satisfaction, good conversion and selectivity were observed with $\mathrm{Pd}(\mathrm{OAc})_{2}$ and compound $3 \mathbf{a}$ was obtained in $60 \%$ yield (Table 1 , entry 7 ). More importantly, the use of 1.3 equiv. of phenylboronic acid for a longer time afforded compound $3 \mathbf{a}$ in better yield ( $64 \%$, Table 1, entry 12). No yield improvement for compound 3a was observed when we carried out the reaction in presence of Xantphos (Table 1, entry 8) or increased the temperature (Table 1, entries 10 and 11). Moderate selectivity was obtained when $\mathrm{PPh}_{3}$ was added (Table 1, entry 9). These trials with different catalysts revealed that regioselectivity depends on the catalytic system: $\mathrm{Pd}(\mathrm{OAc})_{2}$ performed best, both on conversion and selectivity, in our reaction conditions.

Table 1. Optimization of the regioselective Suzuki-Miyaura reaction.

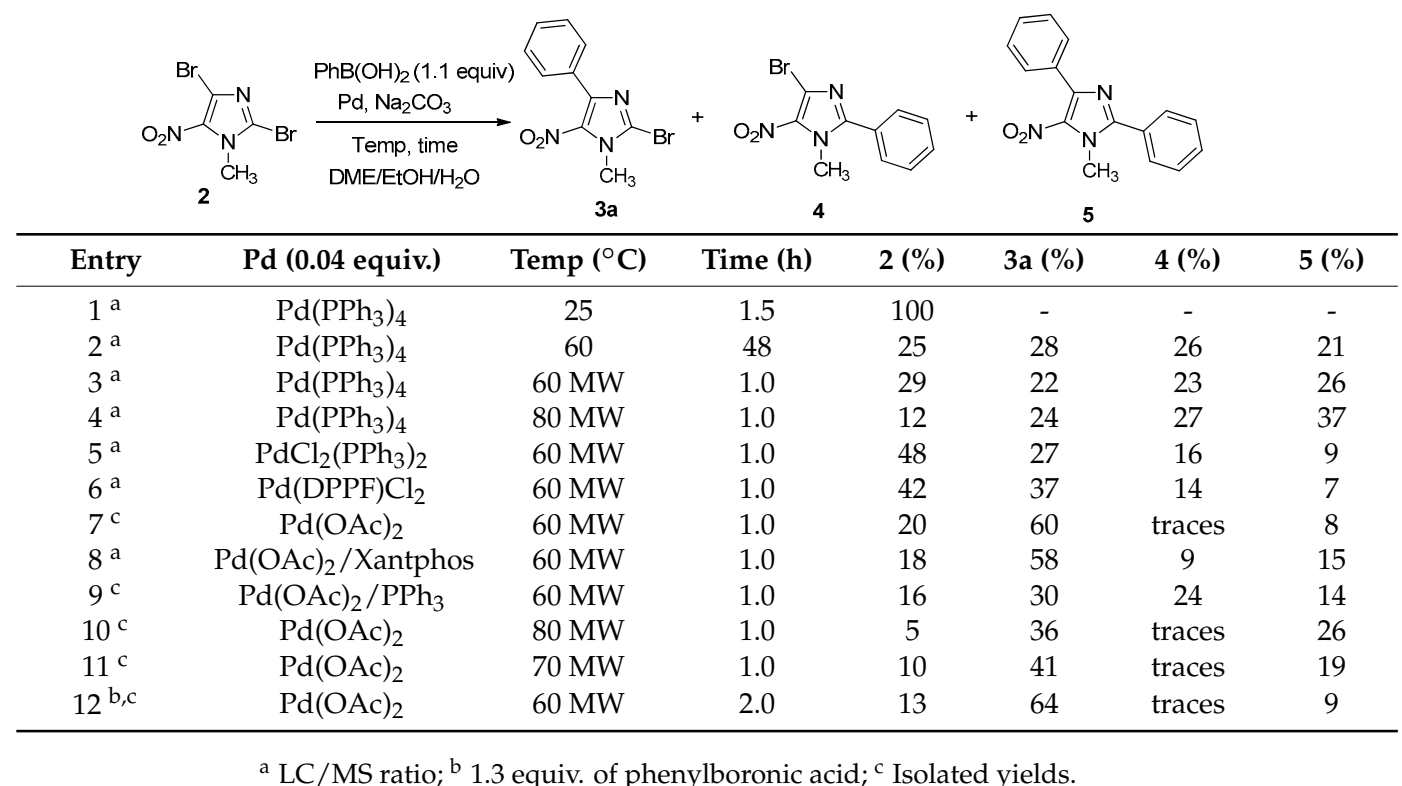

So, the best reaction conditions were 1 equivalent of imidazole 2, 1.3 equivalents of phenyl-boronic acid, 0.04 equivalents of palladium acetate and 3 equivalents of sodium carbonate in DME $/ \mathrm{EtOH} / \mathrm{H}_{2} \mathrm{O}$ $(3 / 1 / 1)$ for $2 \mathrm{~h}$ at $60{ }^{\circ} \mathrm{C}$ under microwave irradiation. With the optimized reaction conditions in hand, we assessed the scope and limitations of the regioselective Suzuki-Miyaura reaction of 2,4-dibromo-1-methyl-5-nitro-1H-imidazole (2). A variety of substituted arylboronic acids (with both electron-donating or electron-withdrawing groups) were used to give the corresponding coupling products $3 \mathbf{a}-\mathbf{i}$ in moderate to good yields (55-65\%). However, the use of hydroxymethylphenylboronic acid (3i) and boronic acids substituted by withdrawing groups such as $\mathrm{NO}_{2}$ or $\mathrm{CF}_{3}$ required a temperature increase to $65{ }^{\circ} \mathrm{C}$ (Table 2, Compounds 3c, 3d). On the other hand, the use of 
heteroarylboronic acids (pyridine-3-ylboronic acid, 5-methylthiophen-2-ylboronic acid) led to very low conversion under our optimal conditions. Increasing the temperature in these cases improved the yield of the corresponding dicoupled product.

Table 2. Scope of the regioselective Suzuki-Miyaura reaction.

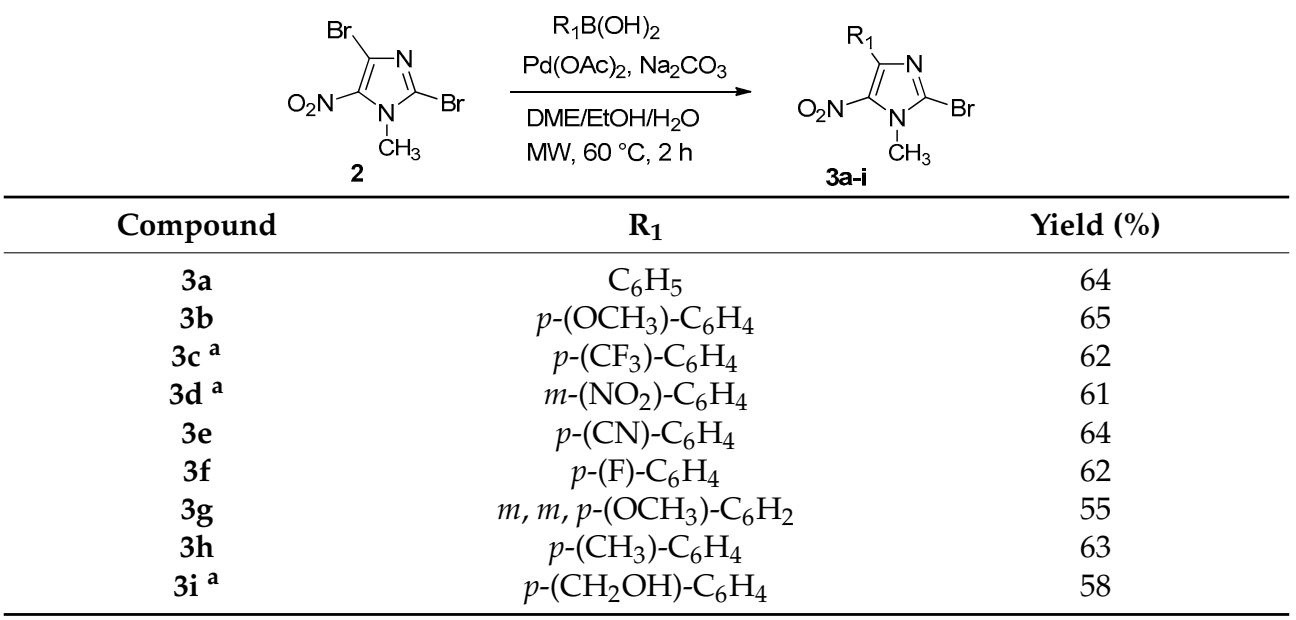

Reaction conditions: boronic acids (1.3 equiv.), $\mathrm{Pd}(\mathrm{OAc})_{2}$ (0.04 equiv.), $\mathrm{Na}_{2} \mathrm{CO}_{3}$ (3 equiv.), $\mathrm{DME} / \mathrm{EtOH} / \mathrm{H}_{2} \mathrm{O}(3 / 1 / 1)$, $\mathrm{MW}, 60^{\circ} \mathrm{C}, 2 \mathrm{~h} .{ }^{\mathrm{a}} \mathrm{MW}, 65^{\circ} \mathrm{C}, 2 \mathrm{~h}$.

The X-ray crystal structure (Figure 1) was determined for compound 3c to confirm the regioselective Suzuki-Miyaura reaction on 4-position of 2,4-dibromo-1-methyl-5-nitro- $1 H$ imidazole (2).

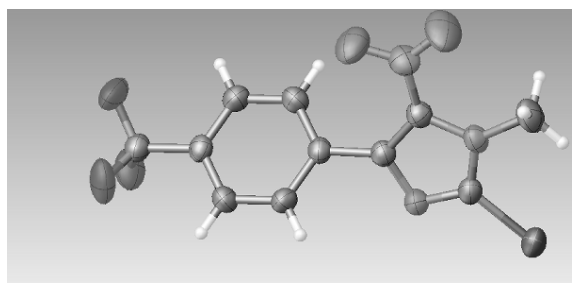

Figure 1. X-ray crystal structure of compound 3c.

Following optimization of the regioselective Suzuki-Miyaura reaction, we investigated the one-pot regioselective bis-Suzuki-Miyaura reactions of 2,4-dibromo-1-methyl-5-nitro-1H-imidazole (2).

The sequential one-pot two-step bis-Suzuki-Miyaura reactions of compound 2 were studied using phenylboronic acid and 4-methoxyphenylboronic acid under microwave irradiation. Phenylboronic acid can be expected to react selectively at the C-4 position, with the subsequent addition of 4-methoxyphenylboronic acid leading to reaction at the C-2 position of compound 2 (Table 3).

The first step was performed in the presence of phenylboronic acid (1.3 equiv.), $\mathrm{Pd}(\mathrm{OAc})_{2}$ (0.04 equiv.), $\mathrm{Na}_{2} \mathrm{CO}_{3}$ (3 equiv.) in $\mathrm{DME} / \mathrm{EtOH} / \mathrm{H}_{2} \mathrm{O}(3 / 1 / 1)$ at $60{ }^{\circ} \mathrm{C}$ under microwave irradiation for $2 \mathrm{~h}$. In the second step, the reaction was carried out without addition of a palladium catalyst and in presence of 4-methoxyphenylboronic acid (1.3 equiv.), $\mathrm{Na}_{2} \mathrm{CO}_{3}$ (3 equiv.) at $60{ }^{\circ} \mathrm{C}$ under microwave irradiation for $1 \mathrm{~h}$, giving the expected disubstituted imidazole 6 in moderate yield (22\%, Table 3, entry 1). These conditions did not allow a complete conversion of the intermediate compound $\mathbf{3 a}$, which remains the majority product with a yield of $47 \%$. Adding $\mathrm{Pd}(\mathrm{OAc})_{2}(0.04$ equiv.) in the second step increased the yield of compound 6 to $30 \%$ (Table 3, entry 2). Performing the reaction at $110{ }^{\circ} \mathrm{C}$ increased the yield of compound 6 to $40 \%$ (Table 3, entry 3). Interestingly, using $\mathrm{Pd}_{(}\left(\mathrm{PPh}_{3}\right)_{4}(0.04$ equiv.) or adding only $\mathrm{PPh}_{3}$ (0.1 equiv.) in the second step led to complete conversion of the intermediate $3 \mathbf{a}$ and the corresponding product 6 isolated respectively in 60 and 64\% yields (Table 3, entries 4 
and 5). Note that, when the reaction temperature was reduced to $90{ }^{\circ} \mathrm{C}$, incomplete conversion of the intermediate 3a was observed (according to LC/MS analysis).

Table 3. Optimization of the second step of the one-pot regioselective bis-Suzuki-Miyaura reaction.

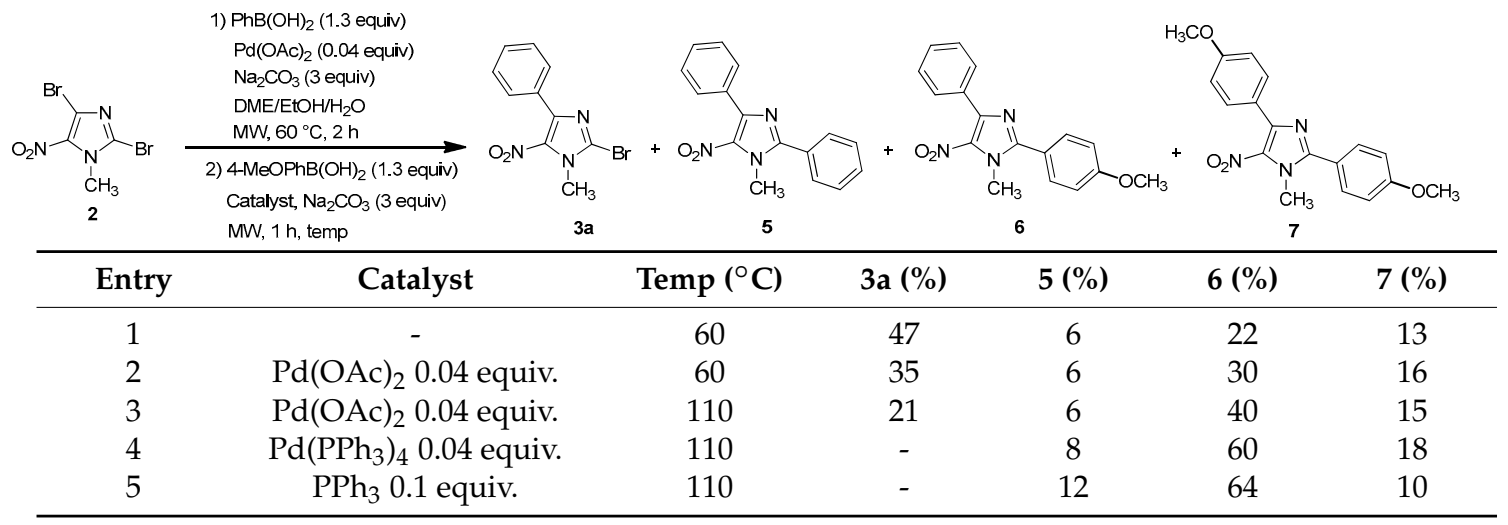

In addition, the use of 4-methoxyphenylboronic acid in the first step and phenylboronic acid in the second step gave the corresponding product 6 a in better yield (71\%, Scheme 2).
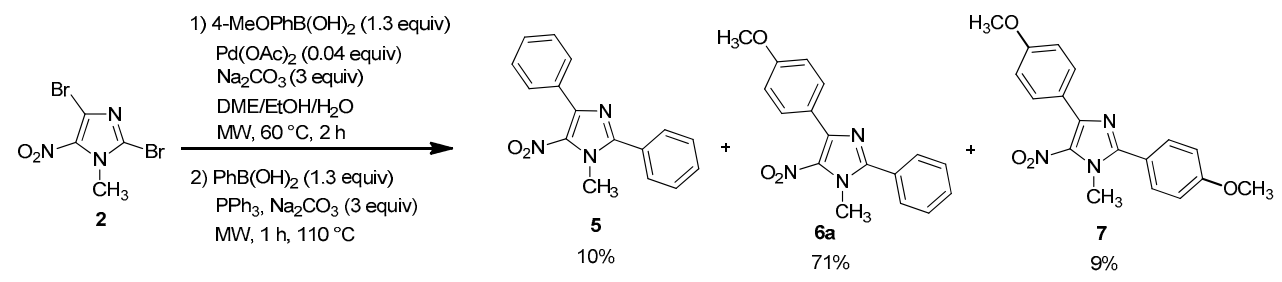

Scheme 2. One-pot regioselective bis-Suzuki-Miyaura reaction.

With optimized conditions established, the scope of the one-pot regioselective bis-Suzuki-Miyaura reaction was explored using a variety of (hetero)arylboronic acids. We chose 4-methoxy-phenylboronic acid for the first step and different boronic acids for the second step (Table 4). This approach enabled a broad range of (hetero)arylboronic acids bearing an electron-donating or withdrawing group to be used under standard conditions, and provided the disubstituted imidazole derivatives $6 \mathbf{6}-\mathbf{j}$ in moderate to good yields (Table 4, 50-71\%).

In view of these encouraging results, we then turned our attention to the sequential one-pot regioselective Suzuki-Miyaura/Sonogashira reaction of 2,4-dibromo-1-methyl-5-nitro- $1 \mathrm{H}$-imidazole (2). Having optimized reaction conditions for the regioselective Suzuki-Miyaura coupling, we decided to develop the one-pot Suzuki-Miyaura/Sonogashira sequence.

Thus, based on the already optimized regioselective Suzuki-Miyaura reaction conditions and the classical conditions for Sonogashira reaction, we prepared the disubstituted 5-nitroimidazole derivative 8a from 4-methoxyphenylboronic acid and ethynylbenzene (Scheme 3). The first step was performed in presence of 4-methoxyphenylboronic acid (1.3 equiv.), $\mathrm{Na}_{2} \mathrm{CO}_{3}$ (3 equiv.), $\mathrm{Pd}(\mathrm{OAc})_{2}$ (0.04 equiv.) in a mixture of DME/ $\mathrm{EtOH} / \mathrm{H}_{2} \mathrm{O}(3 / 1 / 1)$ under microwave irradiation for $2 \mathrm{~h}$ at $60{ }^{\circ} \mathrm{C}$. After cooling, ethynylbenzene (1.3 equiv.), $\mathrm{PPh}_{3}$ (0.1 equiv.), $\mathrm{CuI}$ (0.1 equiv.) and $\mathrm{Et}_{3} \mathrm{~N}$ (2 equiv.) were added and the mixture was heated again under microwave irradiation for $1 \mathrm{~h}$ at $70{ }^{\circ} \mathrm{C}$. This sequence led to the desired compound 8a in good yield (67\%) and compounds 7 and 9 in 11\% and 10\% yields, respectively (Scheme 3).

The scope of this Suzuki-Miyaura/Sonogashira sequence was then investigated using the optimized procedure. We were pleased to observe the formation of the disubstituted imidazole derivatives 8a-j in moderate to good yields when 4-methoxyphenylboronic acid was used in the first 
step and various terminal alkynes in the second step (Table 5). Both electron-poor (compounds $\mathbf{8 c}, \mathbf{8 h}$ and $\mathbf{8 i}$ ) and electron-rich (compounds $\mathbf{8 b}, \mathbf{8 d}$ and $\mathbf{8 f}$ ) substituents on aryl alkynes are well tolerated. Interestingly, this strategy was also tolerant to cycloalkyl alkynes (compounds $\mathbf{8 e}$ and $\mathbf{8 j}$ ) and to a hydroxyl moiety (compound 8g).

Table 4. Scope of one-pot regioselective bis-Suzuki-Miyaura reaction. ${ }^{\text {a }}$

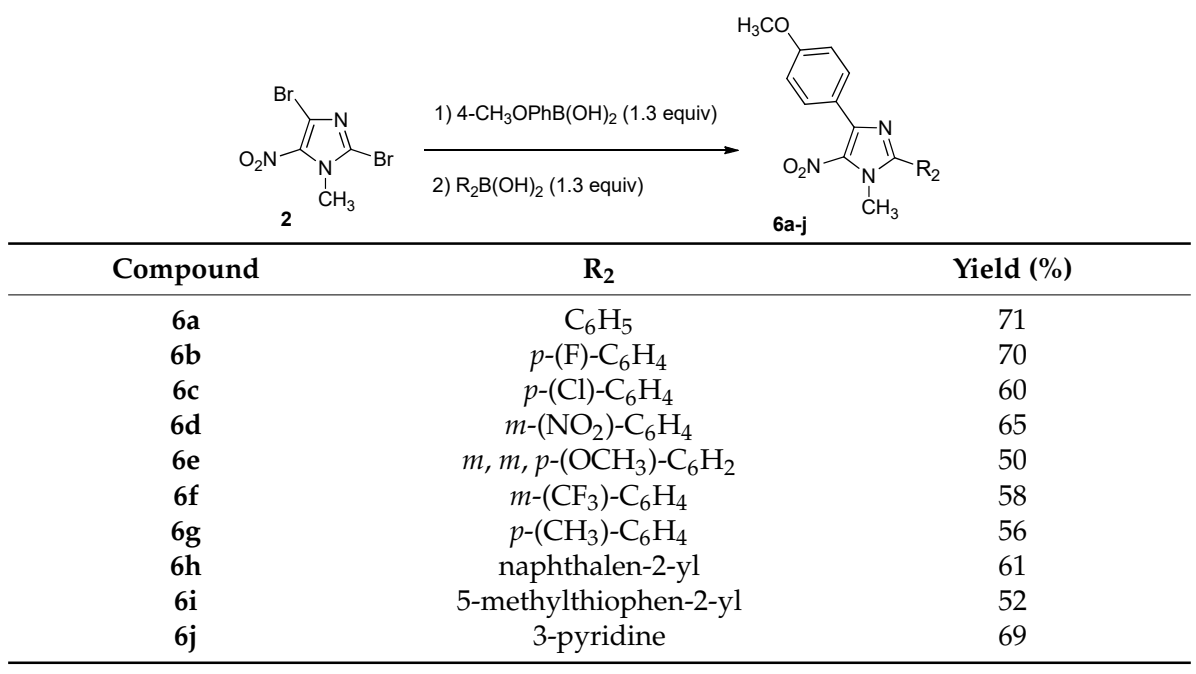

a Reaction conditions: Step 1: 4-methoxyphenylboronic acid (1.3 equiv.), $\mathrm{Pd}(\mathrm{OAc})_{2}$ (0.04 equiv.), $\mathrm{Na}_{2} \mathrm{CO}_{3}$ ( 3 equiv.), $\mathrm{DME} / \mathrm{EtOH} / \mathrm{H}_{2} \mathrm{O}(3 / 1 / 1), \mathrm{MW}, 60^{\circ} \mathrm{C}, 2 \mathrm{~h}$; Step 2: boronic acid (1.3 equiv.), $\mathrm{PPh}_{3}$ (0.1 equiv.), $\mathrm{Na}_{2} \mathrm{CO}_{3}$ ( 3 equiv.), $\mathrm{MW}, 110{ }^{\circ} \mathrm{C}, 1 \mathrm{~h}$.

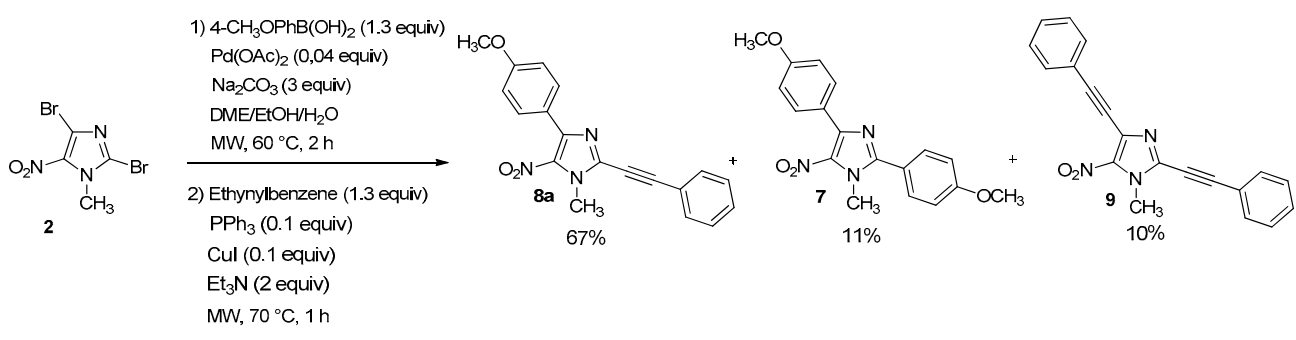

Scheme 3. One-pot regioselective Suzuki-Miyaura/Sonogashira reaction.

Table 5. Scope of the one-pot Suzuki-Miyaura/Sonogashira reaction. ${ }^{\text {a }}$

\begin{tabular}{|c|c|c|}
\hline 2 & $\begin{array}{l}\text { 1) 4-Methoxyphenylbronic acid } \\
\text { 2) } \mathrm{R}_{3}=\mathrm{H}\end{array}$ & \\
\hline Compound & $\mathbf{R}_{\mathbf{3}}$ & Yield (\%) \\
\hline $8 a$ & $\mathrm{C}_{6} \mathrm{H}_{5}$ & 67 \\
\hline $8 b$ & $m-\left(\mathrm{CH}_{3}\right)-\mathrm{C}_{6} \mathrm{H}_{4}$ & 74 \\
\hline $8 c$ & $m$-fluoro- $\mathrm{C}_{6} \mathrm{H}_{4}$ & 59 \\
\hline $8 d$ & $o-\left(\mathrm{CH}_{3}\right)-p-\left(\mathrm{OCH}_{3}\right)-\mathrm{C}_{6} \mathrm{H}_{3}$ & 53 \\
\hline $8 \mathbf{e}$ & cyclopentyl & 60 \\
\hline $8 f$ & $p$-(tert-butyl)- $\mathrm{C}_{6} \mathrm{H}_{4}$ & 63 \\
\hline $8 g$ & $\mathrm{CH}_{2} \mathrm{OH}$ & 51 \\
\hline $8 \mathrm{~h}$ & $m$-chloro- $\mathrm{C}_{6} \mathrm{H}_{4}$ & 61 \\
\hline $8 \mathrm{i}$ & $o$-chloro- $\mathrm{C}_{6} \mathrm{H}_{4}$ & 52 \\
\hline $8 \mathbf{j}$ & cyclopropyl & 63 \\
\hline
\end{tabular}

a Reaction conditions: Step 1: 4-methoxyphenylboronic acid (1.3 equiv.), $\mathrm{Pd}(\mathrm{OAc})_{2}\left(0.04\right.$ equiv.), $\mathrm{Na}_{2} \mathrm{CO}_{3}$ (3 equiv.), $\mathrm{DME} / \mathrm{EtOH} / \mathrm{H}_{2} \mathrm{O}(3 / 1 / 1), \mathrm{MW}, 60^{\circ} \mathrm{C}, 2$ h; Step 2: alkyne (1.3 equiv.), $\mathrm{PPh}_{3}$ (0.1 equiv.), $\mathrm{Et}_{3} \mathrm{~N}$ (2 equiv.), CuI (0.1 equiv.), $\mathrm{MW}, 70^{\circ} \mathrm{C}, 1 \mathrm{~h}$. 


\subsection{Antimicrobial Activity}

The antimicrobial activity of the newly synthesized products was evaluated against anaerobic Gram positive bacteria of the genus Clostridium and Bacillus. They were also evaluated for their antiparasitic activity against $T$. vaginalis. Metronidazole $(\mathrm{mtz})$ was used as control drug to evaluate the potency of the tested compounds under the same conditions.

\subsubsection{Antibacterial Activity}

Antibacterial activity was determined by the disc diffusion method, according to European committee on Antimicrobial Susceptibility Testing (EUCAST) recommendations [62]. We first screened the 27 molecules synthesized for their antibacterial activity against $C$. butyricum, C. perfringens, C. neonatale, C. difficile, B. circulans and E. coli. The observed data on the antibacterial activity of the 3 series of compounds are reported for compounds 3a-3i in Table 6, for compounds $6 \mathbf{a}-\mathbf{6} \mathbf{j}$ in Table 7 , and for compounds $\mathbf{8 a - 8 j}$ in Table 8 . Molecules are considered active when the inhibition diameter is larger than $20 \mathrm{~mm}$, and very active when it is larger than the inhibition diameter of metronidazole.

Table 6. Antibacterial activity of molecules $3 \mathbf{a}-\mathbf{3 i}$ obtained with the first regioselective Suzuki-Miyaura reaction.

\begin{tabular}{ccccccccccc}
\hline \multirow{2}{*}{ Bacterial Species } & \multicolumn{10}{c}{ Compounds } \\
\cline { 2 - 12 } & $\mathbf{3 a}$ & $\mathbf{3 b}$ & $\mathbf{3 c}$ & $\mathbf{3 d}$ & $\mathbf{3 e}$ & $\mathbf{3 f}$ & $\mathbf{3 g}$ & $\mathbf{3 h}$ & $\mathbf{3 i}$ & $\mathbf{m t z}$ \\
\hline C. butyricum Nec 0 & 14 & 38 & 0 & 26 & 18 & 14 & 27 & 21 & 0 & $>30$ \\
C. perfringens & $>20$ & 0 & 0 & 0 & 0 & 0 & 0 & 0 & 0 & $<20$ \\
C. neonatale & 25 & 29 & 14 & $>20$ & 24 & 28 & 30 & 25 & 22 & 32 \\
C. difficile & $>20$ & 31 & 15 & 10 & 25 & 28 & 23 & 29 & 32 & $>20$ \\
B. circulans & 0 & 0 & 0 & 0 & 0 & 0 & 0 & 0 & 0 & $<20$ \\
E. coli & 0 & 0 & 0 & 0 & 0 & 0 & 0 & 0 & 0 & 0 \\
\hline
\end{tabular}

Inhibition zone diameter (mm).

Table 7. Antibacterial activity of molecules $\mathbf{6 a}-\mathbf{j}$ obtained with the one-pot regioselective bis-Suzuki-Miyaura reaction.

\begin{tabular}{cccccccccc}
\hline \multirow{2}{*}{ Bacterial Species } & \multicolumn{10}{c}{ Compounds } \\
\cline { 2 - 10 } & $\mathbf{6 a}$ & $\mathbf{6 c}$ & $\mathbf{6 d}$ & $\mathbf{6 e}$ & $\mathbf{6 g}$ & $\mathbf{6 h}$ & $\mathbf{6 i}$ & $\mathbf{6 j}$ & $\mathbf{m t z}$ \\
\hline C. butyricum Nec 0 & 24 & 20 & 29 & 14 & 0 & 0 & 25 & $>20$ & $>30$ \\
C. perfringens & 0 & 0 & 0 & 0 & 0 & $>20$ & 0 & 0 & $<20$ \\
C. neonatale & 22 & $>20$ & $>20$ & $>20$ & 14 & 0 & $>20$ & $>20$ & 32 \\
C. difficile & 23 & 12 & 14 & 14 & 16 & 13 & 0 & 15 & $>20$ \\
B. circulans & 0 & 0 & 0 & 0 & 0 & 0 & 0 & 0 & $<20$ \\
E. coli & 0 & 0 & 0 & 0 & 0 & 0 & 0 & 0 & 0 \\
\hline
\end{tabular}

Inhibition zone diameter (mm).

Table 8. Antibacterial activity of molecules $8 \mathbf{a}-\mathbf{j}$ obtained with the one-pot Suzuki-Miyaura/ Sonogashira reaction.

\begin{tabular}{ccccccccccc}
\hline \multirow{2}{*}{ Bacterial Species } & \multicolumn{10}{c}{ Compounds } \\
\cline { 2 - 11 } & $\mathbf{8 a}$ & $\mathbf{8 b}$ & $\mathbf{8 c}$ & $\mathbf{8 d}$ & $\mathbf{8 e}$ & $\mathbf{8 g}$ & $\mathbf{8 h}$ & $\mathbf{8 i}$ & $\mathbf{8 j}$ & $\mathbf{m t z}$ \\
\hline C. butyricum Nec 0 & 0 & 25 & 0 & 0 & 17 & 17 & 8 & 18 & 23 & $>30$ \\
C. perfringens & 0 & 0 & 0 & 24 & 0 & 0 & $>20$ & 0 & 0 & $<20$ \\
C. neonatale & 11 & $>20$ & 29 & 0 & 15 & 23 & 0 & 13 & 18 & 32 \\
C. difficile & 0 & 13 & 0 & 0 & 17 & 20 & 0 & 0 & 19 & $>20$ \\
B. circulans & 0 & 0 & 0 & 0 & 0 & 0 & 0 & 0 & 0 & $<20$ \\
E. coli & 0 & 0 & 0 & 0 & 0 & 0 & 0 & 0 & 0 & 0 \\
\hline \multicolumn{1}{c}{ Inhibition zone diameter $(\mathrm{mm})}$.
\end{tabular}


Results show that none of the molecules tested, including metronidazole, were active on facultative anaerobic bacteria (B. circulans) and aerobic bacteria (E. coli). Indeed, to be active, 5-nitro-imidazole compounds must undergo a reduction of their nitro group which can only be carried out in an anaerobic environment [2]. If the molecules were active on aerobic bacteria, this would suggest another mechanism of action.

For the anaerobic bacteria, it was observed that compounds $\mathbf{3 b}, \mathbf{3} \mathbf{e}-\mathbf{i}$ (Table 6), with a bromine in 2-position, possessed an activity on C. butyricum Nec 0, C. neonatale and C. difficile equivalent or higher than the standard metronidazole. On the other hand, compounds $\mathbf{6 a}-\mathbf{j}$ (Table 7) with an aryl group in 2-position had a lower activity than compounds $3 \mathbf{a}-\mathbf{j}$. Only compound $\mathbf{6 a}$ was active on C. butyricum $\mathrm{Nec}$ 0, C. neonatale and C. difficile. Compounds 8a-j, the last series, with an alkyne in 2-position, had a lower activity than the molecules of the first two series (Table 8).

The second step consisted in testing the most active molecules, $\mathbf{3 b}, \mathbf{3} \mathbf{e}-\mathbf{i}$ on other particularly virulent bacteria such as B. cereus, C. beijerenckii, C. tetani and C. difficile 027 (Table 9). The first results showed that a bromine in 2-position could improve the activity of our compounds, so, we decided to test the starting compound 2 with two bromine atoms in 2 and 4-position. Unfortunately, this last compound did not exhibit any activity (Table 9). Whatever the nature of the aryl group in 4-position, the molecules with a bromine in 2-position (3b, 3e-3i) had promising activity on C. butyricum Nec 0 , $\mathrm{Nec} 1, \mathrm{Nec} 8$ and on C. difficile O27. One of them, compound $3 \mathrm{~g}$, with a trimethoxyphenyl group in 4-position, exhibited higher activity against C. butyricum Nec 8 than metronidazole. It was thus observed from the investigation on anaerobic bacteria screening data that the combination of a bromine atom in 2-position and an aryl group in 4-position enhanced the compounds' antibacterial activities.

Table 9. Antibacterial activity of the most promising molecules.

\begin{tabular}{ccccccccc}
\hline \multirow{2}{*}{ Bacterial Species } & \multicolumn{8}{c}{ Compounds } \\
\cline { 2 - 9 } & $\mathbf{2}$ & $\mathbf{3 b}$ & $\mathbf{3 e}$ & $\mathbf{3 f}$ & $\mathbf{3 g}$ & $\mathbf{3 h}$ & $\mathbf{3 i}$ & $\mathbf{~ m t z}$ \\
\hline B. cereus & 0 & 10.9 & 9.6 & 9.6 & 10.9 & 10.7 & 11.5 & 0 \\
B. beijerenckii & 0 & 0 & 0 & 9 & 0 & 0 & 0 & 11 \\
C. butyricum Nec 0 & 0 & 29.4 & 24.6 & 26.7 & 30.4 & 27.6 & 30.2 & 31 \\
C. butyricum Nec 1 & 0 & 32.8 & 27 & 29.8 & 32.2 & 29.3 & 34.1 & 34 \\
C. butyricum Nec 8 & 0 & 31.3 & 24.8 & 27.8 & 34.5 & 27.8 & 32 & 30 \\
C. tetani & 0 & 0 & 0 & 0 & 0 & 0 & 0 & 56 \\
C. perfringens & 0 & 0 & 20 & 0 & 26 & 0 & 29 & 30 \\
C. difficile O27 & 5.8 & 32.4 & 35 & 30.6 & 33.7 & 29.7 & 32.8 & 37 \\
\hline
\end{tabular}

Inhibition zone diameter (mm).

\subsubsection{Antiparasitic Activity}

We selected the six molecules $\mathbf{3} \mathbf{b}, \mathbf{3 e}-\mathbf{3} \mathbf{i}$ showing the most promising activities against anaerobic bacteria, and assessed their therapeutic interest on T. vaginalis by determining minimum inhibitory concentration (MIC, Table 10). We also performed a cytotoxicity evaluation via the Neutral Red Uptake (NRU) toxicity test [63] on CHO-K1 Chinese Hamster Ovary cells (ATCC CCL61) to detect cytotoxic concentrations of $50 \%\left(\mathrm{CC}_{50}\right)$. This procedure enabled us to determine the selectivity index of these 6 compounds (Table 10), all of which are shown to have a significantly higher activity, with lower MICs, than metronidazole. On the other hand, they have a significant and higher toxicity than metronidazole, especially for compounds $\mathbf{3 b}, \mathbf{3} \mathbf{f}$ and $\mathbf{3} \mathbf{i}$ with methoxyphenyl, fluorophenyl or hydroxymethylphenyl groups in the 4-position. 
Table 10. Antiparasitic evaluation on T. vaginalis.

\begin{tabular}{cccc}
\hline Compounds & Activity T. vaginalis $\mathbf{M I C}(\boldsymbol{\mu M})$ & ${\text { Cytotoxicity } \mathbf{C C}_{\mathbf{5 0}}(\boldsymbol{\mu M})}_{\text {Selectivity Index }^{\mathbf{a}}}$ \\
\hline $\mathbf{3 b}$ & 4.00 & 2.58 & 0.64 \\
$\mathbf{3 e}$ & 4.07 & - & - \\
$\mathbf{3 f}$ & 1.04 & 1.72 & 1.65 \\
$\mathbf{3 g}$ & 0.84 & 2.59 & 3.08 \\
$\mathbf{3 h}$ & 1.05 & 3.59 & 3.42 \\
$\mathbf{3 i}$ & 0.99 & 1.13 & 1.13 \\
$\mathbf{m t z}$ & 7.30 & 557.34 & 18.65 \\
\hline
\end{tabular}

${ }^{\text {a }}$ Selectivity index calculated according to the formula: $\mathrm{IC}_{50} / \mathrm{MIC}$.

\subsubsection{Cytotoxicity Evaluation}

The molecules with an aryl $(\mathbf{6 a} \mathbf{a}-\mathbf{j})$ or alkyne $(\mathbf{8 a}-\mathbf{j})$ group at 2-position show cytotoxicity equivalent to that of molecules with a bromine in 2-position (3a-i) (Table 11). The homogeneity of the cytotoxicity of our molecules in the three different series shows the importance of the substituent at the 2-position of the imidazole nucleus.

Table 11. Cytotoxicity evaluation on Chinese Hamster Ovary cells.

\begin{tabular}{cc}
\hline Compounds & Cytotoxicity $\mathrm{CC}_{\mathbf{5 0}}(\boldsymbol{\mu M})$ \\
\hline $\mathbf{3 a}$ & 1.89 \\
$\mathbf{3 b}$ & 2.58 \\
$\mathbf{3 d}$ & 1.87 \\
$\mathbf{3 f}$ & 1.72 \\
$\mathbf{3 g}$ & 2.59 \\
$\mathbf{3 h}$ & 3.59 \\
$\mathbf{3 i}$ & 1.13 \\
\hline $\mathbf{6 a}$ & 3.21 \\
$\mathbf{6 c}$ & 1.41 \\
$\mathbf{6 d}$ & 6.94 \\
$\mathbf{6 e}$ & 0.90 \\
$\mathbf{6 g}$ & 2.97 \\
$\mathbf{6 h}$ & 0.83 \\
$\mathbf{6 i}$ & 1.48 \\
$\mathbf{6 j}$ & 1.24 \\
\hline $\mathbf{8 a}$ & 2.65 \\
$\mathbf{8 b}$ & 1.33 \\
$\mathbf{8 c}$ & 1.35 \\
$\mathbf{8 d}$ & 0.43 \\
$\mathbf{8 e}$ & 2.39 \\
$\mathbf{8 g}$ & 0.27 \\
$\mathbf{8 h}$ & 4.57 \\
$\mathbf{8 i}$ & 2.73 \\
$\mathbf{8 j}$ & 1.17 \\
\hline $\mathbf{m t z}$ & 557.34 \\
\hline
\end{tabular}

\section{Experimental Section}

\subsection{General Information}

Melting points were determined on Büchi B-540 (BÜCHI Labortechnik AG, Flawil, Switzerland) and are uncorrected. Elemental analyses and HRMS were carried out at the Spectropole, Faculté des Sciences et Techniques de Saint-Jérôme, Marseille. Elemental analyses were performed on a EA1112 instrument (Thermo Finnigan, San Jose, CA, USA). HRMS spectra were recorded on a 
QStar Elite (Applied Biosystems SCIEX, Foster City, CA, USA) spectrometer. PEG was a matrix for HRMS. LC/MS analyses were performed at the Faculté de Pharmacie de Marseille on an Accela High System ${ }^{\circledR}$ chain U-HPLC coupled with a Thermo MSQ Plus ${ }^{\circledR}$ simple quadrupole. A Thermo Hypersil Gold ${ }^{\circledR} 50 \times 2.1 \mathrm{~mm}$ chromatographic column was used $\left(\mathrm{SiO}_{2} \mathrm{C} 18\right)$ with $1.9 \mu \mathrm{m}$ diameter particles. Analysis is 8 min running, with an $\mathrm{MeOH} / \mathrm{H}_{2} \mathrm{O}$ eluent gradient from $50 / 50$ to 95/05. Both ${ }^{1} \mathrm{H}-\mathrm{NMR}$ spectra $\left(250 \mathrm{MHz}\right.$, reference $\left.\mathrm{CDCl}_{3} \delta=7.26,\left[d_{6}\right] \mathrm{DMSO} \delta=2.50\right)$ and ${ }^{13} \mathrm{C}-\mathrm{NMR}$ spectra $(62.5 \mathrm{MHz}$, reference $\left.\mathrm{CDCl}_{3} \delta=77.0,\left[d_{6}\right] \mathrm{DMSO} \delta=39.7\right)$ were recorded at $24{ }^{\circ} \mathrm{C}$ on an ARX 250 spectrometer (Bruker, Wissembourg, France) in $\mathrm{CDCl}_{3}$ and $\left[d_{6}\right]$ DMSO solvents at the Faculté de Pharmacie de Marseille. Solvents were dried by conventional methods. The following adsorbent was used for column chromatography: silica gel 60 (Merck, Darmstadt, Germany, particle size 0.063-0.200 mm, 70-230 mesh ASTM). TLC was performed on $5 \mathrm{~cm} \times 10 \mathrm{~cm}$ aluminium plates coated with silica gel 60F-254 (Merck) in an appropriate eluent. Microwave reactions were performed with an Initiator microwave oven (Biotage ${ }^{\circledR}$, Charlotte, NC, USA) using 2-5 mL sealed vials; temperatures were measured with an IR-sensor and reaction times are given as hold times.

\subsection{Chemistry}

\subsubsection{2,4-Dibromo-1-methyl-5-nitro-1H-imidazole (2)}

First step: to a solution of 4(5)-nitro- $1 \mathrm{H}$-imidazole ( $20 \mathrm{~g}, 177 \mathrm{mmol}), \mathrm{NaHCO}_{3}$ ( $44.6 \mathrm{~g}, 3$ equiv., $531 \mathrm{mmol})$ in water $(120 \mathrm{~mL})$ was added dropwise at $0{ }^{\circ} \mathrm{C}$ dibromine $(27 \mathrm{~mL}, 3$ equiv., $531 \mathrm{mmol})$ and the reaction mixture was heated at $65^{\circ} \mathrm{C}$ for $6 \mathrm{~h}$. After cooling, the solution was poured into bath of ice. A yellow precipitate appeared and was filtered, washed with water $(3 \times 100 \mathrm{~mL})$ and dried in vacuum drying oven (dessicator cabinet). The aqueous layer was extracted with ethyle acetate $(3 \times 100 \mathrm{~mL})$ and the organic layer was washed with brine $(3 \times 100 \mathrm{~mL})$, dried over $\mathrm{Na}_{2} \mathrm{SO}_{4}$ and evaporated. Yellow solid was obtained and added to the precipitate to give $36.3 \mathrm{~g}(80 \%)$ of 2,4(5)-dibromo-5(4)-nitroimidazole.

Second step; to a solution of 2,4(5)-dibromo-5(4)-nitroimidazole (34 g, $126 \mathrm{mmol})$ in DMF (80 mL) was added dropwise at $0{ }^{\circ} \mathrm{C}$ dimethyl sulfate $(13.1 \mathrm{~mL}, 1.1$ equiv., $138 \mathrm{mmol})$ and the reaction mixture was heated at $100{ }^{\circ} \mathrm{C}$ for $2 \mathrm{~h}$. After cooling, the solution was treated with a saturated solution of sodium hydrogen carbonate at $0{ }^{\circ} \mathrm{C}$. A white precipitate appeared and was filtered. One part of the precipitate was solubilised in ethyl acetate and evaporated after filtration. The precipitate not dissolved was the 2,5-dibromo-1-methyl-4-nitro- $1 \mathrm{H}$-imidazole (1, 38\%, 14 g), M.p. $192{ }^{\circ} \mathrm{C}$ (lit. [26] 204-205 ${ }^{\circ} \mathrm{C}$ ). ${ }^{1} \mathrm{H}-\mathrm{NMR}\left(\mathrm{CDCl}_{3}\right): \delta=3.75\left(\mathrm{~s}, 3 \mathrm{H}, \mathrm{NCH}_{3}\right)$ ppm. ${ }^{13} \mathrm{C}-\mathrm{NMR}\left(\mathrm{CDCl}_{3}\right): \delta=35.0\left(\mathrm{NCH}_{3}\right), 106.7\left(\mathrm{C}_{\mathrm{Ar}}\right)$, $120.4\left(\mathrm{C}_{\mathrm{Ar}}\right) \mathrm{ppm}\left(\mathrm{CNO}_{2}\right.$ was not visible under these conditions). The aqueous layer was extracted with ethyl acetate $(3 \times 100 \mathrm{~mL})$ and the organic layer was washed with brine $(3 \times 100 \mathrm{~mL})$, dried over $\mathrm{Na}_{2} \mathrm{SO}_{4}$ and evaporated. The crude product was purified by column chromatography [silica gel, petroleum ether/ethyl acetate $(9 / 1)$ and the 2,4-dibromo-1-methyl-5-nitro- $1 \mathrm{H}$-imidazole (2) was obtained in $33 \%$ in yield (12.1 g). M.p. $167^{\circ} \mathrm{C}$ (lit. [42] 160-161 $\left.{ }^{\circ} \mathrm{C}\right) .{ }^{1} \mathrm{H}-\mathrm{NMR}\left(\mathrm{CDCl}_{3}\right): \delta=4.02(\mathrm{~s}, 3 \mathrm{H}$, $\left.\mathrm{NCH}_{3}\right)$ ppm. ${ }^{13} \mathrm{C}-\mathrm{NMR}\left(\mathrm{CDCl}_{3}\right): \delta=37.2\left(\mathrm{NCH}_{3}\right), 119.8\left(\mathrm{C}_{\mathrm{Ar}}\right), 126.4\left(\mathrm{C}_{\mathrm{Ar}}\right) \mathrm{ppm}\left(\mathrm{CNO}_{2}\right.$ was not visible under these conditions).

\subsubsection{General Procedure for the Regioselective Suzuki-Miyaura Coupling Reaction}

A solution of 2,4-dibromo-1-methyl-5-nitro- $1 \mathrm{H}$-imidazole $(2,0.1 \mathrm{~g}, 0.35 \mathrm{mmol})$, boronic acid ( $0.46 \mathrm{mmol}, 1.3$ equiv.), $\mathrm{Pd}(\mathrm{OAc})_{2}$ ( $3 \mathrm{mg}, 0.014 \mathrm{mmol}, 0.04$ equiv.), $\mathrm{Na}_{2} \mathrm{CO}_{3}(0.11 \mathrm{~g}, 1.05 \mathrm{mmol}, 3$ equiv.), in a DME/EtOH/ $\mathrm{H}_{2} \mathrm{O}$ mixture $(3 / 1 / 1,5 \mathrm{~mL})$ was heated at $60{ }^{\circ} \mathrm{C}$ under microwave irradiation for $2 \mathrm{~h}$. After cooling, $60 \mathrm{~mL}$ of water were added and the solution was extracted with dichloromethane $(3 \times 50 \mathrm{~mL})$. The organic layer was washed with water $(3 \times 100 \mathrm{~mL})$, dried over $\mathrm{Na}_{2} \mathrm{SO}_{4}$ and evaporated. The crude product was purified by column chromatography [silica gel, petroleum ether/ethyl acetate $(9 / 1),(1 / 1$ for $3 \mathbf{i})$, cyclohexane/ethyl acetate $(9 / 1$ for $3 \mathbf{a})]$ and recrystallized from propan-2-ol. 
2-Bromo-1-methyl-5-nitro-4-phenyl-1H-imidazole (3a): Yield 64\% (63 mg); yellow solid; M.p. $96{ }^{\circ} \mathrm{C}$. ${ }^{1} \mathrm{H}-\mathrm{NMR}\left(\mathrm{CDCl}_{3}\right): \delta=4.01\left(\mathrm{~s}, 3 \mathrm{H}, \mathrm{NCH}_{3}\right), 7.43-7.45(\mathrm{~m}, 3 \mathrm{H}, 3 \mathrm{Ar}-\mathrm{H}), 7.73-7.77(\mathrm{~m}, 2 \mathrm{H}, 2 \mathrm{Ar}-\mathrm{H}) \mathrm{ppm}$. ${ }^{13} \mathrm{C}-\mathrm{NMR}\left(\mathrm{CDCl}_{3}\right): \delta=36.5\left(\mathrm{NCH}_{3}\right), 126.6\left(\mathrm{C}_{\mathrm{Ar}}\right), 128.1\left(2 \mathrm{CH}_{\mathrm{Ar}}\right), 129.5\left(2 \mathrm{CH}_{\mathrm{Ar}}\right), 129.9\left(\mathrm{CH}_{\mathrm{Ar}}\right), 130.7$ $\left(\mathrm{C}_{\mathrm{Ar}}\right), 136.0\left(\mathrm{C}_{\mathrm{Ar}}\right), 144.3\left(\mathrm{C}_{\mathrm{Ar}}\right)$ ppm. HRMS (ESI) $m / z[\mathrm{M}+\mathrm{H}]^{+}$calcd. for $\left[\mathrm{C}_{10} \mathrm{H}_{8} \mathrm{BrN}_{3} \mathrm{O}_{2}\right]^{+}: 281.9873$; found 281.9874 .

2-Bromo-4-(4-methoxypheny)-1-methyl-5-nitro-1H-imidazole (3b): Yield 65\% (71 mg); orange solid; M.p. $125{ }^{\circ} \mathrm{C} .{ }^{1} \mathrm{H}-\mathrm{NMR}\left(\mathrm{CDCl}_{3}\right): \delta=3.86\left(\mathrm{~s}, 3 \mathrm{H}, \mathrm{NCH}_{3}\right), 4.00\left(\mathrm{~s}, 3 \mathrm{H}, \mathrm{OCH}_{3}\right), 6.95\left(\mathrm{~d},{ }^{3} J_{\mathrm{H}-\mathrm{H}}=8.9 \mathrm{~Hz}\right.$, 2H, $2 \mathrm{Ar}-\mathrm{H}), 7.77\left(\mathrm{~d},{ }^{3} \mathrm{~J}_{\mathrm{H}-\mathrm{H}}=8.8 \mathrm{~Hz}, 2 \mathrm{H}, 2 \mathrm{Ar}-\mathrm{H}\right) \mathrm{ppm} .{ }^{13} \mathrm{C}-\mathrm{NMR}\left(\mathrm{CDCl}_{3}\right): \delta=36.6\left(\mathrm{NCH}_{3}\right), 55.3$ $\left(\mathrm{OCH}_{3}\right), 113.6\left(2 \mathrm{CH}_{\mathrm{Ar}}\right), 123.0\left(\mathrm{C}_{\mathrm{Ar}}\right), 126.8\left(\mathrm{C}_{\mathrm{Ar}}\right), 131.3\left(2 \mathrm{CH}_{\mathrm{Ar}}\right), 135.8\left(\mathrm{C}_{\mathrm{Ar}}\right), 144.5\left(\mathrm{C}_{\mathrm{Ar}}\right), 161.0\left(\mathrm{C}_{\mathrm{Ar}}\right)$ ppm. HRMS (ESI) $m / z[\mathrm{M}+\mathrm{H}]^{+}$calcd. for $\left[\mathrm{C}_{11} \mathrm{H}_{10} \mathrm{BrN}_{3} \mathrm{O}_{3}\right]^{+}:$311.9978; found 311.9977 .

2-Bromo-1-methyl-5-nitro-4-[4-(trifluoromethyl)phenyl]-1H-imidazole (3c): Yield 62\% (76 mg); yellow solid; M.p. $102{ }^{\circ} \mathrm{C} .{ }^{1} \mathrm{H}-\mathrm{NMR}\left(\mathrm{CDCl}_{3}\right): \delta=4.03\left(\mathrm{~s}, 3 \mathrm{H}, \mathrm{NCH}_{3}\right), 7.69\left(\mathrm{~d},{ }^{3} \mathrm{~J}_{\mathrm{H}-\mathrm{H}}=8.2 \mathrm{~Hz}, 2 \mathrm{H}, 2 \mathrm{Ar}-\mathrm{H}\right), 8.87$ $\left(\mathrm{d},{ }^{3} J_{\mathrm{H}-\mathrm{H}}=8.2 \mathrm{~Hz}, 2 \mathrm{H}, 2 \mathrm{Ar}-\mathrm{H}\right) \mathrm{ppm} .{ }^{13} \mathrm{C}-\mathrm{NMR}\left(\mathrm{CDCl}_{3}\right): \delta=36.6\left(\mathrm{NCH}_{3}\right), 123.9\left(\mathrm{q},{ }^{1} J_{\mathrm{C}-\mathrm{F}}=272.4 \mathrm{~Hz}\right.$, $\left.\mathrm{CF}_{3}\right), 125.1\left(\mathrm{q},{ }^{3} J_{\mathrm{C}-\mathrm{F}}=3.9 \mathrm{~Hz}, 2 \mathrm{CH}_{\mathrm{Ar}}\right), 126.9(\mathrm{C}), 129.9\left(2 \mathrm{CH}_{\mathrm{Ar}}\right), 131.6\left(\mathrm{q},{ }^{2} J_{\mathrm{C}-\mathrm{F}}=32.5 \mathrm{~Hz}, \mathrm{C}_{\mathrm{Ar}}\right), 134.2$ $\left(\mathrm{C}_{\mathrm{Ar}}\right), 136.3\left(\mathrm{C}_{\mathrm{Ar}}\right), 142.4\left(\mathrm{C}_{\mathrm{Ar}}\right)$ ppm. HRMS (ESI) $m / z[\mathrm{M}+\mathrm{H}]^{+}$calcd. for $\left[\mathrm{C}_{11} \mathrm{H}_{7} \mathrm{BrF}_{3} \mathrm{~N}_{3} \mathrm{O}_{2}\right]^{+}:$349.9746; found 349.9744 .

2-Bromo-1-methyl-5-nitro-4-(3-nitrophenyl)-1H-imidazole (3d): Yield 61\% (70 mg); yellow solid; M.p. $166{ }^{\circ} \mathrm{C} .{ }^{1} \mathrm{H}-\mathrm{NMR}\left(\mathrm{CDCl}_{3}\right): \delta=4.06\left(\mathrm{~s}, 3 \mathrm{H}, \mathrm{NCH}_{3}\right), 7.63\left(\mathrm{t},{ }^{3} J_{\mathrm{H}-\mathrm{H}}=8.2 \mathrm{~Hz}, 1 \mathrm{H}, \mathrm{Ar}-\mathrm{H}\right), 8.10$ $\left(\mathrm{d},{ }^{3} \mathrm{~J}_{\mathrm{H}-\mathrm{H}}=7.7 \mathrm{~Hz}, 1 \mathrm{H}, \mathrm{Ar}-\mathrm{H}\right), 8.28-8.32(\mathrm{~m}, 1 \mathrm{H}, \mathrm{Ar}-\mathrm{H}), 8.66(\mathrm{~s}, 1 \mathrm{H}, \mathrm{Ar}-\mathrm{H}) \mathrm{ppm} .{ }^{13} \mathrm{C}-\mathrm{NMR}\left(\mathrm{CDCl}_{3}\right)$ : $\delta=36.8\left(\mathrm{NCH}_{3}\right), 124.5\left(\mathrm{CH}_{\mathrm{Ar}}\right), 124.8\left(\mathrm{CH}_{\mathrm{Ar}}\right), 127.1\left(\mathrm{C}_{\mathrm{Ar}}\right), 129.2\left(\mathrm{CH}_{\mathrm{Ar}}\right), 132.4\left(\mathrm{C}_{\mathrm{Ar}}\right), 135.4\left(\mathrm{CH}_{\mathrm{Ar}}\right), 136.3$ $\left(\mathrm{C}_{\mathrm{Ar}}\right), 141.5\left(\mathrm{C}_{\mathrm{Ar}}\right), 148.0\left(\mathrm{C}_{\mathrm{Ar}}\right)$ ppm. Anal. Calcd. for $\mathrm{C}_{10} \mathrm{H}_{7} \mathrm{BrN}_{4} \mathrm{O}_{4}$ (327.09): C 36.72, $\mathrm{H} 2.16, \mathrm{~N} 17.13$; found C 36.82, H 2.06, N 17.13 .

4-(2-Bromo-1-methyl-5-nitro-1H-imidazol-4-yl)benzonitrile (3e): Yield 64\% (69 mg); yellow solid; M.p. $155{ }^{\circ} \mathrm{C} .{ }^{1} \mathrm{H}-\mathrm{NMR}\left(\mathrm{CDCl}_{3}\right): \delta=4.04\left(\mathrm{~s}, 3 \mathrm{H}, \mathrm{NCH}_{3}\right), 7.73\left(\mathrm{~d},{ }^{3} \mathrm{~J}_{\mathrm{H}-\mathrm{H}}=8.5 \mathrm{~Hz}, 2 \mathrm{H}, 2 \mathrm{Ar}-\mathrm{H}\right), 7.88$ $\left(\mathrm{d},{ }^{3} J_{\mathrm{H}-\mathrm{H}}=8.5 \mathrm{~Hz}, 2 \mathrm{H}, 2 \mathrm{Ar}-\mathrm{H}\right) \mathrm{ppm} .{ }^{13} \mathrm{C}-\mathrm{NMR}\left(\mathrm{CDCl}_{3}\right): \delta=35.8\left(\mathrm{NCH}_{3}\right), 113.3(\mathrm{C}), 118.4\left(\mathrm{C}_{\mathrm{Ar}}\right), 127.1$ $\left(\mathrm{C}_{\mathrm{Ar}}\right), 130.2\left(2 \mathrm{CH}_{\mathrm{Ar}}\right), 131.9\left(2 \mathrm{CH}_{\mathrm{Ar}}\right), 135.0\left(\mathrm{C}_{\mathrm{Ar}}\right), 136.4\left(\mathrm{C}_{\mathrm{Ar}}\right), 141.8\left(\mathrm{C}_{\mathrm{Ar}}\right) \mathrm{ppm}$. HRMS (ESI) $\mathrm{m} / z$ $[\mathrm{M}+\mathrm{H}]^{+}$calcd. for $\left[\mathrm{C}_{11} \mathrm{H}_{7} \mathrm{BrN}_{4} \mathrm{O}_{2}\right]^{+}$: 306.9825; found 306.9824 .

2-Bromo-4-(4-fluorophenyl)-1-methyl-5-nitro-1H-imidazole (3f): Yield 62\% (65 mg); yellow solid; M.p. $112{ }^{\circ} \mathrm{C} .{ }^{1} \mathrm{H}-\mathrm{NMR}\left(\mathrm{CDCl}_{3}\right): \delta=4.01\left(\mathrm{~s}, 3 \mathrm{H}, \mathrm{NCH}_{3}\right), 7.08-7.15(\mathrm{~m}, 2 \mathrm{H}, 2 \mathrm{Ar}-\mathrm{H}), 7.74-7.80(\mathrm{~m}, 2 \mathrm{H}, 2 \mathrm{Ar}-\mathrm{H})$ ppm. ${ }^{13} \mathrm{C}-\mathrm{NMR}\left(\mathrm{CDCl}_{3}\right): \delta=36.6\left(\mathrm{NCH}_{3}\right), 115.2\left(\mathrm{~d},{ }^{2} J_{\mathrm{C}-\mathrm{F}}=21.5 \mathrm{~Hz}, 2 \mathrm{CH}_{\mathrm{Ar}}\right), 126.7\left(\mathrm{C}_{\mathrm{Ar}}\right), 126.8\left(\mathrm{C}_{\mathrm{Ar}}\right)$, $131.7\left(\mathrm{~d},{ }^{3} J_{\mathrm{C}-\mathrm{F}}=8.8 \mathrm{~Hz}, 2 \mathrm{CH}_{\mathrm{Ar}}\right), 135.9\left(\mathrm{C}_{\mathrm{Ar}}\right), 143.3\left(\mathrm{C}_{\mathrm{Ar}}\right), 163.6\left(\mathrm{~d},{ }^{1} J_{\mathrm{C}-\mathrm{F}}=250.9 \mathrm{~Hz}, \mathrm{C}_{\mathrm{Ar}}\right)$ ppm. Anal. Calcd. for $\mathrm{C}_{10} \mathrm{H}_{7} \mathrm{BrFN}_{3} \mathrm{O}_{2}$ (300.08): C 40.02, H 2.35, N 14.00; found C 39.86, H 2.23, N 13.80.

2-Bromo-1-methyl-5-nitro-4-(3,4,5-trimethoxyphenyl)-1H-imidazole (3g): Yield 55\% (72 mg); yellow solid; M.p. $134{ }^{\circ} \mathrm{C} .{ }^{1} \mathrm{H}-\mathrm{NMR}\left(\mathrm{CDCl}_{3}\right): \delta=3.89\left(\mathrm{~s}, 9 \mathrm{H}, \mathrm{NCH}_{3}, 2 \mathrm{OCH}_{3}\right), 4.00\left(\mathrm{~s}, 3 \mathrm{H}, \mathrm{OCH}_{3}\right), 7.07(\mathrm{~s}, 2 \mathrm{H}$, $2 \mathrm{Ar}-\mathrm{H}), \mathrm{ppm} .{ }^{13} \mathrm{C}-\mathrm{NMR}\left(\mathrm{CDCl}_{3} \delta=36.7\left(\mathrm{NCH}_{3}\right), 56.2\left(2 \mathrm{OCH}_{3}\right), 60.9\left(\mathrm{OCH}_{3}\right), 107.0\left(2 \mathrm{CH}_{\mathrm{Ar}}\right), 107.4\right.$ $\left(\mathrm{C}_{\mathrm{Ar}}\right), 125.7\left(\mathrm{C}_{\mathrm{Ar}}\right), 126.6\left(\mathrm{C}_{\mathrm{Ar}}\right), 139.6\left(\mathrm{C}_{\mathrm{Ar}}\right), 144.0\left(\mathrm{C}_{\mathrm{Ar}}\right), 152.8\left(2 \mathrm{C}_{\mathrm{Ar}}\right) \mathrm{ppm}$. HRMS (ESI) $m / z[\mathrm{M}+\mathrm{H}]^{+}$ calcd. for $\left[\mathrm{C}_{13} \mathrm{H}_{14} \mathrm{BrN}_{3} \mathrm{O}_{5}\right]^{+}$: 372.0190; found 372.0187.

2-Bromo-1-methyl-5-nitro-4-p-tolyl-1H-imidazole (3h): Yield 63\% (65 mg); yellow solid; M.p. $160{ }^{\circ} \mathrm{C}$. ${ }^{1} \mathrm{H}-\mathrm{NMR}\left(\mathrm{CDCl}_{3}\right): \delta=2.40\left(\mathrm{~s}, 3 \mathrm{H}, \mathrm{CH}_{3}\right), 4.01\left(\mathrm{~s}, 3 \mathrm{H}, \mathrm{NCH}_{3}\right), 7.24\left(\mathrm{~d},{ }^{3} \mathrm{~J}_{\mathrm{H}-\mathrm{H}}=8.2 \mathrm{~Hz}, 2 \mathrm{H}, 2 \mathrm{CH}\right.$ ar $), 7.66$ $\left(\mathrm{d},{ }^{3} J_{\mathrm{H}-\mathrm{H}}=8.2 \mathrm{~Hz}, 2 \mathrm{H}, 2 \mathrm{CH}\right.$ ar) ppm. ${ }^{13} \mathrm{C}-\mathrm{NMR}\left(\mathrm{CDCl}_{3}\right): \delta=21.4\left(\mathrm{CH}_{3}\right), 36.5\left(\mathrm{NCH}_{3}\right), 125.4\left(\mathrm{C}_{\mathrm{Ar}}\right)$, $126.6\left(\mathrm{C}_{\mathrm{Ar}}\right), 127.8\left(\mathrm{C}_{\mathrm{Ar}}\right), 128.9\left(2 \mathrm{CH}_{\mathrm{Ar}}\right), 129.4\left(2 \mathrm{CH}_{\mathrm{Ar}}\right), 140.2\left(\mathrm{C}_{\mathrm{Ar}}\right), 144.5\left(\mathrm{C}_{\mathrm{Ar}}\right)$ ppm. Anal. Calcd. for $\mathrm{C}_{11} \mathrm{H}_{10} \mathrm{BrN}_{3} \mathrm{O}_{2}$ (296.12): C 44.62, H 3.40, N 14.19; found C 44.63, H 3.27, N 13.95.

[4-(2-Bromo-1-methyl-5-nitro-1H-imidazol-4-yl)phenyl]methanol (3i): Yield 58\% (65 mg); yellow solid; M.p. $132{ }^{\circ} \mathrm{C} .{ }^{1} \mathrm{H}-\mathrm{NMR}\left(\mathrm{DMSO}-d_{6}\right): \delta=3.91\left(\mathrm{~s}, 3 \mathrm{H}, \mathrm{NCH}_{3}\right), 4.55\left(\mathrm{~d},{ }^{3} \mathrm{~J}_{\mathrm{H}-\mathrm{H}}=5.8 \mathrm{~Hz}, 2 \mathrm{H}, \mathrm{CH}_{2}\right), 5.29(\mathrm{t}$, $\left.{ }^{3} J_{\mathrm{H}-\mathrm{H}}=5.7 \mathrm{~Hz}, 1 \mathrm{H}, \mathrm{OH}\right), 7.40\left(\mathrm{~d},{ }^{3} J_{\mathrm{H}-\mathrm{H}}=8.2 \mathrm{~Hz}, 2 \mathrm{H}, 2 \mathrm{Ar}-\mathrm{H}\right), 7.63\left(\mathrm{~d},{ }^{3} J_{\mathrm{H}-\mathrm{H}}=8.2 \mathrm{~Hz}, 2 \mathrm{H}, 2 \mathrm{Ar}-\mathrm{H}\right) \mathrm{ppm}$. ${ }^{13} \mathrm{C}-\mathrm{NMR}\left(\mathrm{DMSO}-\mathrm{d}_{6}\right): \delta=36.7\left(\mathrm{NCH}_{3}\right), 62.8\left(\mathrm{CH}_{2}\right), 126.1\left(2 \mathrm{CH}_{\mathrm{Ar}}\right), 127.4\left(\mathrm{C}_{\mathrm{Ar}}\right), 129.1\left(2 \mathrm{CH}_{\mathrm{Ar}}\right), 129.6$ 
$\left(\mathrm{C}_{\mathrm{Ar}}\right), 136.1\left(\mathrm{C}_{\mathrm{Ar}}\right), 143.0\left(\mathrm{C}_{\mathrm{Ar}}\right), 144.3\left(\mathrm{C}_{\mathrm{Ar}}\right)$ ppm. Anal. Calcd. for $\mathrm{C}_{11} \mathrm{H}_{10} \mathrm{BrN}_{3} \mathrm{O}_{3}$ (312.12): $\mathrm{C} 42.33, \mathrm{H}$ 3.23, N 13.46; found C 42.34, H 3.11, N 13.33 .

1-Methyl-5-nitro-2-4-diphenyl-1H-imidazole (5): Yield 9\% using general procedure for the regioselective Suzuki-Miyaura coupling reaction $(9 \mathrm{mg})$; yellow solid; M.p. $129^{\circ} \mathrm{C} .{ }^{1} \mathrm{H}-\mathrm{NMR}\left(\mathrm{CDCl}_{3}\right)$ : $\delta=4.00\left(\mathrm{~s}, 3 \mathrm{H}, \mathrm{NCH}_{3}\right), 7.44-7.47(\mathrm{~m}, 3 \mathrm{H}, 3 \mathrm{Ar}-\mathrm{H}), 7.54-7.56(\mathrm{~m}, 3 \mathrm{H}, 3 \mathrm{Ar}-\mathrm{H}), 7.69-7.72(\mathrm{~m}, 2 \mathrm{H}, 2 \mathrm{Ar}-\mathrm{H})$, 7.83-7.87 (m, 2H, $2 \mathrm{Ar}-\mathrm{H})$ ppm. ${ }^{13} \mathrm{C}-\mathrm{NMR}\left(\mathrm{CDCl}_{3}\right): \delta=36.2\left(\mathrm{NCH}_{3}\right), 128.1\left(2 \mathrm{CH}_{\mathrm{Ar}}\right), 128.3\left(\mathrm{C}_{\mathrm{Ar}}\right), 128.9$ $\left(2 \mathrm{CH}_{\mathrm{Ar}}\right), 129.5\left(\mathrm{CH}_{\mathrm{Ar}}\right), 129.7\left(4 \mathrm{CH}_{\mathrm{Ar}}\right), 130.7\left(\mathrm{CH}_{\mathrm{Ar}}\right), 131.7\left(\mathrm{C}_{\mathrm{Ar}}\right), 135.9\left(\mathrm{C}_{\mathrm{Ar}}\right), 144.2\left(\mathrm{C}_{\mathrm{Ar}}\right), 150.5\left(\mathrm{C}_{\mathrm{Ar}}\right)$ ppm. Anal. Calcd. for $\mathrm{C}_{16} \mathrm{H}_{13} \mathrm{~N}_{3} \mathrm{O}_{2}$ (279.29): C 68.71, H 4.69, N 15.05; found C 68.43, H 4.62, N 14.85.

\subsubsection{General Procedure for the One-Pot Regioselective Bis-Suzuki-Miyaura Coupling Reaction}

A solution of 2,4-dibromo-1-methyl-5-nitro-1H-imidazole $(2,0.1 \quad \mathrm{~g}, \quad 0.35 \mathrm{mmol})$, 4-methoxy-phenylboronic acid $\left(72 \mathrm{mg}, 0.46 \mathrm{mmol}, 1.3\right.$ equiv.), $\mathrm{Pd}(\mathrm{OAc})_{2}$ ( $3 \mathrm{mg}, 0.014 \mathrm{mmol}$, 0.04 equiv.), $\mathrm{Na}_{2} \mathrm{CO}_{3}\left(0.11 \mathrm{~g}, 1.05 \mathrm{mmol}, 3\right.$ equiv.), in a DME/EtOH $/ \mathrm{H}_{2} \mathrm{O}$ mixture $(3 / 1 / 1,5 \mathrm{~mL})$ was heated at $60{ }^{\circ} \mathrm{C}$ under microwave irradiation for $2 \mathrm{~h}$. After cooling, boronic acid $(0.45 \mathrm{mmol}$, 1.3 equiv.), $\mathrm{PPh}_{3}$ (9 mg, $0.035 \mathrm{mmol}, 0.1$ equiv.), $\mathrm{Na}_{2} \mathrm{CO}_{3}(0.11 \mathrm{~g}, 1.05 \mathrm{mmol}, 3$ equiv.), were introduced under argon. The mixture was heated at $110{ }^{\circ} \mathrm{C}$ for $1 \mathrm{~h}$ under microwave irradiation. After cooling, $60 \mathrm{~mL}$ of water were added and the solution was extracted with dichloromethane $(3 \times 50 \mathrm{~mL})$. The organic layer was washed with water $(3 \times 100 \mathrm{~mL})$, dried over $\mathrm{Na}_{2} \mathrm{SO}_{4}$ and evaporated. The crude product was purified by column chromatography [silica gel, petroleum ether/ethyl acetate (9/1), (7/3 for $6 \mathbf{e}),(5 / 5$ for $6 \mathbf{j})]$ and recrystallized from propan-2-ol.

4-(4-Methoxyphenyl)-1-methyl-5-nitro-2-phenyl-1H-imidazole (6a): Yield 71\% (77 mg); yellow solid; M.p. $120{ }^{\circ} \mathrm{C} .{ }^{1} \mathrm{H}-\mathrm{NMR}\left(\mathrm{CDCl}_{3}\right): \delta=3.86\left(\mathrm{~s}, 3 \mathrm{H}, \mathrm{NCH}_{3}\right), 3.99\left(\mathrm{~s}, 3 \mathrm{H}, \mathrm{OCH}_{3}\right), 6.98\left(\mathrm{~d},{ }^{3} J_{\mathrm{H}-\mathrm{H}}=8.8 \mathrm{~Hz}\right.$, 2H, 2 Ar-H), 7.53-7.56 (m, 3H, 3 Ar-H), 7.68-7.72 (m, 2H, 2 Ar-H), $7.87\left(\mathrm{~d},{ }^{3} J_{\mathrm{H}-\mathrm{H}}=8.8 \mathrm{~Hz}, 2 \mathrm{H}, 2 \mathrm{Ar}-\mathrm{H}\right)$ ppm. ${ }^{13} \mathrm{C}-\mathrm{NMR}\left(\mathrm{CDCl}_{3}\right): \delta=36.3\left(\mathrm{NCH}_{3}\right), 55.3\left(\mathrm{OCH}_{3}\right), 113.5\left(2 \mathrm{CH}_{\mathrm{Ar}}\right), 123.9\left(\mathrm{C}_{\mathrm{Ar}}\right), 128.3\left(\mathrm{C}_{\mathrm{Ar}}\right), 128.9$ $\left(2 \mathrm{CH}_{\mathrm{Ar}}\right), 129.7\left(2 \mathrm{CH}_{\mathrm{Ar}}\right), 130.7\left(\mathrm{CH}_{\mathrm{Ar}}\right), 131.4\left(2 \mathrm{CH}_{\mathrm{Ar}}\right), 135.6\left(\mathrm{C}_{\mathrm{Ar}}\right), 144.3\left(\mathrm{C}_{\mathrm{Ar}}\right), 150.6\left(\mathrm{C}_{\mathrm{Ar}}\right), 160.7\left(\mathrm{C}_{\mathrm{Ar}}\right)$ ppm. HRMS (ESI) $m / z[\mathrm{M}+\mathrm{H}]^{+}$calcd. for $\left[\mathrm{C}_{17} \mathrm{H}_{15} \mathrm{~N}_{3} \mathrm{O}_{3}\right]^{+}: 310.1186$; found 310.1185.

2-(4-Fluorophenyl)-4-(4-methoxyphenyl)-1-methyl-5-nitro-1H-imidazole (6b): Yield 70\% (80 mg); yellow solid; M.p. $132{ }^{\circ} \mathrm{C} .{ }^{1} \mathrm{H}-\mathrm{NMR}\left(\mathrm{CDCl}_{3}\right): \delta=3.87\left(\mathrm{~s}, 3 \mathrm{H}, \mathrm{NCH}_{3}\right), 3.97\left(\mathrm{~s}, 3 \mathrm{H}, \mathrm{OCH}_{3}\right), 6.98$ $\left(\mathrm{d},{ }^{3} J_{\mathrm{H}-\mathrm{H}}=9.0 \mathrm{~Hz}, 2 \mathrm{H}, 2 \mathrm{Ar}-\mathrm{H}\right), 7.21-7.28(\mathrm{~m}, 2 \mathrm{H}, 2 \mathrm{Ar}-\mathrm{H}), 7.68-7.73(\mathrm{~m}, 2 \mathrm{H}, 2 \mathrm{Ar}-\mathrm{H}), 7.85$ $\left(\mathrm{d},{ }^{3} J_{\mathrm{H}-\mathrm{H}}=9.0 \mathrm{~Hz}, 2 \mathrm{H}, 2 \mathrm{Ar}-\mathrm{H}\right) \mathrm{ppm} .{ }^{13} \mathrm{C}-\mathrm{NMR}\left(\mathrm{CDCl}_{3}\right): \delta=36.3\left(\mathrm{NCH}_{3}\right), 55.4\left(\mathrm{OCH}_{3}\right), 113.6$ $\left(2 \mathrm{CH}_{\mathrm{Ar}}\right), 116.3\left(\mathrm{~d},{ }^{2} J_{\mathrm{C}-\mathrm{F}}=21.6 \mathrm{~Hz}, 2 \mathrm{CH}_{\mathrm{Ar}}\right), 123.9\left(\mathrm{C}_{\mathrm{Ar}}\right), 123.6\left(\mathrm{C}_{\mathrm{Ar}}\right), 131.4\left(2 \mathrm{CH}_{\mathrm{Ar}}\right), 131.9(\mathrm{~d}$, $\left.{ }^{3} J_{\mathrm{C}-\mathrm{F}}=8.7 \mathrm{~Hz}, 2 \mathrm{CH}_{\mathrm{Ar}}\right), 144.3\left(\mathrm{C}_{\mathrm{Ar}}\right), 148.9\left(\mathrm{C}_{\mathrm{Ar}}\right), 149.6\left(\mathrm{C}_{\mathrm{Ar}}\right), 160.0\left(\mathrm{~d},{ }^{1} J_{\mathrm{C}-\mathrm{F}}=272.1 \mathrm{~Hz}, \mathrm{C}_{\mathrm{Ar}}\right), 160.8\left(\mathrm{C}_{\mathrm{Ar}}\right)$ ppm. HRMS (ESI) $m / z[\mathrm{M}+\mathrm{H}]^{+}$calcd. for $\left[\mathrm{C}_{17} \mathrm{H}_{14} \mathrm{FN}_{3} \mathrm{O}_{3}\right]^{+}:$328.1092; found 328.1093 .

2-(4-Chlorophenyl)-4-(4-methoxyphenyl)-1-methyl-5-nitro-1H-imidazole (6c): Yield 60\% (72 mg); yellow solid; M.p. $134{ }^{\circ} \mathrm{C} .{ }^{1} \mathrm{H}-\mathrm{NMR}\left(\mathrm{CDCl}_{3}\right): \delta=3.87\left(\mathrm{~s}, 3 \mathrm{H}, \mathrm{NCH}_{3}\right), 3.98\left(\mathrm{~s}, 3 \mathrm{H}, \mathrm{OCH}_{3}\right), 6.98$ $\left(\mathrm{d},{ }^{3} J_{\mathrm{H}-\mathrm{H}}=9.0 \mathrm{~Hz}, 2 \mathrm{H}, 2 \mathrm{Ar}-\mathrm{H}\right), 7.53\left(\mathrm{~d},{ }^{3} J_{\mathrm{H}-\mathrm{H}}=8.7 \mathrm{~Hz}, 2 \mathrm{H}, 2 \mathrm{Ar}-\mathrm{H}\right), 7.66\left(\mathrm{~d},{ }^{3} J_{\mathrm{H}-\mathrm{H}}=8.7 \mathrm{~Hz}, 2 \mathrm{H}, 2 \mathrm{Ar}-\mathrm{H}\right)$, $7.84\left(\mathrm{~d},{ }^{3} J_{\mathrm{H}-\mathrm{H}}=8.9 \mathrm{~Hz}, 2 \mathrm{H}, 2 \mathrm{Ar}-\mathrm{H}\right) \mathrm{ppm} .{ }^{13} \mathrm{C}-\mathrm{NMR}\left(\mathrm{CDCl}_{3}\right): \delta=36.3\left(\mathrm{NCH}_{3}\right), 55.3\left(\mathrm{OCH}_{3}\right), 113.6$ $\left(2 \mathrm{CH}_{\mathrm{Ar}}\right), 123.8\left(\mathrm{C}_{\mathrm{Ar}}\right), 126.8\left(\mathrm{C}_{\mathrm{Ar}}\right), 129.3\left(2 \mathrm{CH}_{\mathrm{Ar}}\right), 131.0\left(2 \mathrm{CH}_{\mathrm{Ar}}\right), 131.4\left(2 \mathrm{CH}_{\mathrm{Ar}}\right), 134.8\left(\mathrm{C}_{\mathrm{Ar}}\right), 137.1$ $\left(\mathrm{C}_{\mathrm{Ar}}\right), 144.3\left(\mathrm{C}_{\mathrm{Ar}}\right), 149.4\left(\mathrm{C}_{\mathrm{Ar}}\right), 160.8\left(\mathrm{C}_{\mathrm{Ar}}\right)$ ppm. Anal. Calcd. for $\mathrm{C}_{17} \mathrm{H}_{14} \mathrm{ClN}_{3} \mathrm{O}_{3}$ (343.76): C 59.40, $\mathrm{H}$ 4.10, N 12.22; found C 59.16, H 3.82, N 12.31 .

4-(4-Methoxyphenyl)-1-methyl-5-nitro-2-(3-nitrophenyl)-1H-imidazole (6d): Yield 65\% (81 mg); yellow solid; M.p. $192{ }^{\circ} \mathrm{C} .{ }^{1} \mathrm{H}-\mathrm{NMR}\left(\mathrm{CDCl}_{3}\right): \delta=3.87\left(\mathrm{~s}, 3 \mathrm{H}, \mathrm{NCH}_{3}\right), 4.03\left(\mathrm{~s}, 3 \mathrm{H}, \mathrm{OCH}_{3}\right), 6.99(\mathrm{~d}$, $\left.{ }^{3} J_{\mathrm{H}-\mathrm{H}}=8.9 \mathrm{~Hz}, 2 \mathrm{H}, 2 \mathrm{Ar}-\mathrm{H}\right), 7.76\left(\mathrm{t},{ }^{3} J_{\mathrm{H}-\mathrm{H}}=8.0 \mathrm{~Hz}, 1 \mathrm{H}, \mathrm{Ar}-\mathrm{H}\right), 7.85\left(\mathrm{~d},{ }^{3} J_{\mathrm{H}-\mathrm{H}}=8.9 \mathrm{~Hz}, 2 \mathrm{H}, 2 \mathrm{Ar}-\mathrm{H}\right)$, $8.06\left(\mathrm{~d},{ }^{3} J_{\mathrm{H}-\mathrm{H}}=7.7 \mathrm{~Hz}, 1 \mathrm{H}, \mathrm{Ar}-\mathrm{H}\right), 8.42\left(\mathrm{~d},{ }^{3} J_{\mathrm{H}-\mathrm{H}}=8.2 \mathrm{~Hz}, 1 \mathrm{H}, \mathrm{Ar}-\mathrm{H}\right), 8.59\left(\mathrm{t},{ }^{4} J_{\mathrm{H}-\mathrm{H}}=1.7 \mathrm{~Hz}, 1 \mathrm{H}, \mathrm{Ar}-\mathrm{H}\right)$ ppm. ${ }^{13} \mathrm{C}-\mathrm{NMR}\left(\mathrm{CDCl}_{3}\right): \delta=36.3\left(\mathrm{NCH}_{3}\right), 55.4\left(\mathrm{OCH}_{3}\right), 113.6\left(2 \mathrm{CH}_{\mathrm{Ar}}\right), 123.5\left(\mathrm{C}_{\mathrm{Ar}}\right), 124.6\left(\mathrm{CH}_{\mathrm{Ar}}\right)$, 125.2 $\left(\mathrm{CH}_{\mathrm{Ar}}\right), 130.2\left(\mathrm{CH}_{\mathrm{Ar}}\right), 131.3\left(2 \mathrm{CH}_{\mathrm{Ar}}\right), 135.3\left(\mathrm{CH}_{\mathrm{Ar}}\right), 135.9\left(\mathrm{C}_{\mathrm{Ar}}\right), 144.2\left(\mathrm{C}_{\mathrm{Ar}}\right), 147.7\left(\mathrm{C}_{\mathrm{Ar}}\right), 148.4$ $\left(\mathrm{C}_{\mathrm{Ar}}\right), 156.1\left(\mathrm{C}_{\mathrm{Ar}}\right), 160.9\left(\mathrm{C}_{\mathrm{Ar}}\right)$ ppm. Anal. Calcd. for $\mathrm{C}_{17} \mathrm{H}_{14} \mathrm{~N}_{4} \mathrm{O}_{5}$ (354.32): C 57.63, H 3.98, N 15.81; found $\mathrm{C} 57.38, \mathrm{H} 3.79, \mathrm{~N} 15.59$. 
4-(4-Methoxyphenyl)-1-methyl-5-nitro-2-(3,4,5-trimethoxyphenyl)-1H-imidazole (6e): Yield 50\% (70 mg); yellow solid; M.p. $158{ }^{\circ} \mathrm{C} .{ }^{1} \mathrm{H}-\mathrm{NMR}\left(\mathrm{CDCl}_{3}\right): \delta=3.86\left(\mathrm{~s}, 3 \mathrm{H}, \mathrm{NCH}_{3}\right), 3.91\left(\mathrm{~s}, 9 \mathrm{H}, 3 \mathrm{OCH}_{3}\right)$, $3.98\left(\mathrm{~s}, 3 \mathrm{H}, \mathrm{OCH}_{3}\right), 6.87(\mathrm{~s}, 2 \mathrm{H}, 2 \mathrm{Ar}-\mathrm{H}), 6.97\left(\mathrm{~d},{ }^{3} J_{\mathrm{H}-\mathrm{H}}=8.8 \mathrm{~Hz}, 2 \mathrm{H}, 2 \mathrm{Ar}-\mathrm{H}\right), 7.86\left(\mathrm{~d},{ }^{3} J_{\mathrm{H}-\mathrm{H}}=8.8 \mathrm{~Hz}\right.$, 2H, 2 Ar-H) ppm. ${ }^{13} \mathrm{C}-\mathrm{NMR}\left(\mathrm{CDCl}_{3}\right): \delta=36.4\left(\mathrm{NCH}_{3}\right), 55.3\left(\mathrm{OCH}_{3}\right), 56.4\left(2 \mathrm{OCH}_{3}\right), 61.0\left(\mathrm{OCH}_{3}\right), 107.0$ $\left(2 \mathrm{CH}_{\mathrm{Ar}}\right), 113.5\left(2 \mathrm{CH}_{\mathrm{Ar}}\right), 123.6\left(\mathrm{C}_{\mathrm{Ar}}\right), 123.9\left(\mathrm{C}_{\mathrm{Ar}}\right), 131.4\left(2 \mathrm{CH}_{\mathrm{Ar}}\right), 135.6\left(\mathrm{C}_{\mathrm{Ar}}\right), 140.2\left(\mathrm{C}_{\mathrm{Ar}}\right), 144.3\left(\mathrm{C}_{\mathrm{Ar}}\right)$, $150.7\left(\mathrm{C}_{\mathrm{Ar}}\right), 153.5\left(2 \mathrm{C}_{\mathrm{Ar}}\right), 160.7\left(\mathrm{C}_{\mathrm{Ar}}\right)$ ppm. Anal. Calcd. for $\mathrm{C}_{20} \mathrm{H}_{21} \mathrm{~N}_{3} \mathrm{O}_{6}(399.40)$ : C 60.14, H 5.30, N 10.52; found C 59.67, H 5.05, N 10.67 .

4-(4-Methoxyphenyl)-1-methyl-5-nitro-2-[3-(trifluoromethyl)-phenyl]-1H-imidazole (6f): Yield 58\% (76 mg); yellow solid; M.p. $117{ }^{\circ} \mathrm{C} .{ }^{1} \mathrm{H}-\mathrm{NMR}\left(\mathrm{CDCl}_{3}\right): \delta=3.87\left(\mathrm{~s}, 3 \mathrm{H}, \mathrm{NCH}_{3}\right), 4.00\left(\mathrm{~s}, 3 \mathrm{H}, \mathrm{OCH}_{3}\right)$, $6.99\left(\mathrm{~d},{ }^{3} J_{\mathrm{H}-\mathrm{H}}=9.0 \mathrm{~Hz}, 2 \mathrm{H}, 2 \mathrm{Ar}-\mathrm{H}\right), 7.69\left(\mathrm{t},{ }^{3} J_{\mathrm{H}-\mathrm{H}}=7.7 \mathrm{~Hz}, 1 \mathrm{H}, \mathrm{Ar}-\mathrm{H}\right), 7.81-7.90(\mathrm{~m}, 4 \mathrm{H}, 4 \mathrm{Ar}-\mathrm{H})$, $8.00(\mathrm{~s}, 1 \mathrm{H}, \mathrm{Ar}-\mathrm{H}) .{ }^{13} \mathrm{C}-\mathrm{NMR}\left(\mathrm{CDCl}_{3}\right): \delta=36.2\left(\mathrm{NCH}_{3}\right), 55.3\left(\mathrm{OCH}_{3}\right), 113.6\left(2 \mathrm{CH}_{\mathrm{Ar}}\right), 123.5(\mathrm{q}$, $\left.{ }^{1} J_{\mathrm{C}-\mathrm{F}}=272.9 \mathrm{~Hz}, \mathrm{CF}_{3}\right), 123.6\left(\mathrm{C}_{\mathrm{Ar}}\right), 126.7\left(\mathrm{q},{ }^{3} J_{\mathrm{C}-\mathrm{F}}=3.7 \mathrm{~Hz}, \mathrm{CH}_{\mathrm{Ar}}\right), 127.4\left(\mathrm{q},{ }^{3} J_{\mathrm{C}-\mathrm{F}}=3.7 \mathrm{~Hz}, \mathrm{CH}_{\mathrm{Ar}}\right), 129.3$ $\left(\mathrm{C}_{\mathrm{Ar}}\right), 129.6\left(\mathrm{CH}_{\mathrm{Ar}}\right), 131.3\left(2 \mathrm{CH}_{\mathrm{Ar}}\right), 131.7\left(\mathrm{q},{ }^{2} J_{\mathrm{C}-\mathrm{F}}=33.0 \mathrm{~Hz}, \mathrm{C}_{\mathrm{Ar}}\right), 132.8\left(\mathrm{CH}_{\mathrm{Ar}}\right), 135.8\left(\mathrm{C}_{\mathrm{Ar}}\right), 144.2$ $\left(\mathrm{C}_{\text {Ar }}\right), 148.8\left(\mathrm{C}_{\mathrm{Ar}}\right), 160.9\left(\mathrm{C}_{\text {Ar }}\right)$ ppm. HRMS (ESI) $m / z[\mathrm{M}+\mathrm{H}]^{+}$calcd. for $\left[\mathrm{C}_{18} \mathrm{H}_{14} \mathrm{~F}_{3} \mathrm{~N}_{3} \mathrm{O}_{3}\right]^{+}$: 378.1060; found 378.1058 .

4-(4-Methoxyphenyl)-1-methyl-5-nitro-2-p-tolyl-1H-imidazole (6g): Yield 56\% (64 mg); yellow solid; M.p. $136{ }^{\circ} \mathrm{C} .{ }^{1} \mathrm{H}-\mathrm{NMR}\left(\mathrm{CDCl}_{3}\right): \delta=2.45\left(\mathrm{~s}, 3 \mathrm{H}, \mathrm{CH}_{3}\right), 3.86\left(\mathrm{~s}, 3 \mathrm{H}, \mathrm{NCH}_{3}\right), 3.97\left(\mathrm{~s}, 3 \mathrm{H}, \mathrm{OCH}_{3}\right), 6.98(\mathrm{~d}$, $\left.{ }^{3} J_{\mathrm{H}-\mathrm{H}}=8.9 \mathrm{~Hz}, 2 \mathrm{H}, 2 \mathrm{Ar}-\mathrm{H}\right), 7.35\left(\mathrm{~d},{ }^{3} J_{\mathrm{H}-\mathrm{H}}=7.9 \mathrm{~Hz}, 2 \mathrm{H}, 2 \mathrm{Ar}-\mathrm{H}\right), 7.58\left(\mathrm{~d},{ }^{3} J_{\mathrm{H}-\mathrm{H}}=8.2 \mathrm{~Hz}, 2 \mathrm{H}, 2 \mathrm{Ar}-\mathrm{H}\right)$, $7.86\left(\mathrm{~d},{ }^{3} J_{\mathrm{H}-\mathrm{H}}=8.9 \mathrm{~Hz}, 2 \mathrm{H}, 2 \mathrm{Ar}-\mathrm{H}\right) \mathrm{ppm} .{ }^{13} \mathrm{C}-\mathrm{NMR}\left(\mathrm{CDCl}_{3}\right): \delta=21.5\left(\mathrm{CH}_{3}\right), 36.3\left(\mathrm{NCH}_{3}\right), 55.3\left(\mathrm{OCH}_{3}\right)$, $113.5\left(2 \mathrm{CH}_{\mathrm{Ar}}\right), 124.1\left(\mathrm{C}_{\mathrm{Ar}}\right), 125.5\left(\mathrm{C}_{\mathrm{Ar}}\right), 129.5\left(2 \mathrm{CH}_{\mathrm{Ar}}\right), 129.6\left(2 \mathrm{CH}_{\mathrm{Ar}}\right), 131.4\left(2 \mathrm{CH}_{\mathrm{Ar}}\right), 135.6\left(\mathrm{C}_{\mathrm{Ar}}\right)$, 141.1 $\left(\mathrm{C}_{\mathrm{Ar}}\right), 144.5\left(\mathrm{C}_{\mathrm{Ar}}\right), 150.8\left(\mathrm{C}_{\mathrm{Ar}}\right), 160.7\left(\mathrm{C}_{\mathrm{Ar}}\right) \mathrm{ppm}$. Anal. Calcd. for $\mathrm{C}_{18} \mathrm{H}_{17} \mathrm{~N}_{3} \mathrm{O}_{3}$ (323.35): $\mathrm{C}$ 66.86, H 5.30, N 13.00; found C 66.74, H 5.22, N 12.81 .

4-(4-Methoxyphenyl)-1-methyl-2-(naphthalen-2-yl)-5-nitro-1H-imidazole (6h): Yield 61\% (77 mg); yellow solid; M.p. $143{ }^{\circ} \mathrm{C} .{ }^{1} \mathrm{H}-\mathrm{NMR}\left(\mathrm{CDCl}_{3}\right): \delta=3.87\left(\mathrm{~s}, 3 \mathrm{H}, \mathrm{NCH}_{3}\right), 4.05\left(\mathrm{~s}, 3 \mathrm{H}, \mathrm{OCH}_{3}\right), 6.99(\mathrm{~d}$, $\left.{ }^{3} J_{\mathrm{H}-\mathrm{H}}=8.9 \mathrm{~Hz}, 2 \mathrm{H}, 2 \mathrm{Ar}-\mathrm{H}\right), 7.56-7.64(\mathrm{~m}, 2 \mathrm{H}, 2 \mathrm{Ar}-\mathrm{H}), 7.77\left(\mathrm{dd},{ }^{4} J_{\mathrm{H}-\mathrm{H}}=1.6 \mathrm{~Hz},{ }^{3} J_{\mathrm{H}-\mathrm{H}}=8.5 \mathrm{~Hz}, 1 \mathrm{H}\right.$, $\mathrm{Ar}-\mathrm{H}), 7.90\left(\mathrm{~d},{ }^{3} J_{\mathrm{H}-\mathrm{H}}=8.9 \mathrm{~Hz}, 2 \mathrm{H}, 2 \mathrm{Ar}-\mathrm{H}\right), 7.92-7.96(\mathrm{~m}, 2 \mathrm{H}, 2 \mathrm{Ar}-\mathrm{H}), 8.01\left(\mathrm{~d},{ }^{3} J_{\mathrm{H}-\mathrm{H}}=8.5 \mathrm{~Hz}, 1 \mathrm{H}\right.$, Ar-H), $8.22(\mathrm{~s}, 1 \mathrm{H}, \mathrm{Ar}-\mathrm{H}) \mathrm{ppm} .{ }^{13} \mathrm{C}-\mathrm{NMR}\left(\mathrm{CDCl}_{3}\right): \delta=36.4\left(\mathrm{NCH}_{3}\right), 55.3\left(\mathrm{OCH}_{3}\right), 113.6\left(2 \mathrm{CH}_{\mathrm{Ar}}\right), 124.0$ $\left(\mathrm{C}_{\mathrm{Ar}}\right), 125.7\left(\mathrm{C}_{\mathrm{Ar}}\right), 125.9\left(\mathrm{CH}_{\mathrm{Ar}}\right), 127.1\left(\mathrm{CH}_{\mathrm{Ar}}\right), 127.8\left(\mathrm{CH}_{\mathrm{Ar}}\right), 127.9\left(\mathrm{CH}_{\mathrm{Ar}}\right), 128.6\left(\mathrm{CH}_{\mathrm{Ar}}\right), 128.8\left(\mathrm{CH}_{\mathrm{Ar}}\right)$, 130.2 $\left(\mathrm{CH}_{\mathrm{Ar}}\right), 131.4\left(2 \mathrm{CH}_{\mathrm{Ar}}\right), 132.8\left(\mathrm{C}_{\mathrm{Ar}}\right), 134.0\left(\mathrm{C}_{\mathrm{Ar}}\right), 135.8\left(\mathrm{C}_{\mathrm{Ar}}\right), 144.4\left(\mathrm{C}_{\mathrm{Ar}}\right), 150.7\left(\mathrm{C}_{\mathrm{Ar}}\right), 160.8\left(\mathrm{C}_{\mathrm{Ar}}\right)$ ppm. Anal. Calcd. for $\mathrm{C}_{21} \mathrm{H}_{17} \mathrm{~N}_{3} \mathrm{O}_{3}$ (359.38): C 70.18, H 4.77, N 11.69; found C 70.23, H 4.69, N 11.69.

4-(4-Methoxyphenyl)-1-methyl-2-(5-methylthiophen-2-yl)-5-nitro-1H-imidazole (6i): Yield 52\% (60 mg); yellow solid; M.p. $151{ }^{\circ} \mathrm{C} .{ }^{1} \mathrm{H}-\mathrm{NMR}\left(\mathrm{CDCl}_{3}\right): \delta=2.57\left(\mathrm{~s}, 3 \mathrm{H}, \mathrm{CH}_{3}\right), 3.86\left(\mathrm{~s}, 3 \mathrm{H}, \mathrm{NCH}_{3}\right), 4.09(\mathrm{~s}, 3 \mathrm{H}$, $\left.\mathrm{OCH}_{3}\right), 6.86-6.88(\mathrm{~m}, 1 \mathrm{H}, \mathrm{Ar}-\mathrm{H}), 6.97\left(\mathrm{~d},{ }^{3} J_{\mathrm{H}-\mathrm{H}}=9.0 \mathrm{~Hz}, 2 \mathrm{H}, 2 \mathrm{Ar}-\mathrm{H}\right), 7.37\left(\mathrm{~d},{ }^{4} J_{\mathrm{H}-\mathrm{H}}=3.6 \mathrm{~Hz}, 1 \mathrm{H}, \mathrm{Ar}-\mathrm{H}\right)$, $7.85\left(\mathrm{~d},{ }^{3} J_{\mathrm{H}-\mathrm{H}}=9.0 \mathrm{~Hz}, 2 \mathrm{H}, 2 \mathrm{Ar}-\mathrm{H}\right) \mathrm{ppm} .{ }^{13} \mathrm{C}-\mathrm{NMR}\left(\mathrm{CDCl}_{3}\right): \delta=15.4\left(\mathrm{CH}_{3}\right), 36.0\left(\mathrm{NCH}_{3}\right), 55.3\left(\mathrm{OCH}_{3}\right)$, $113.5\left(2 \mathrm{CH}_{\mathrm{Ar}}\right), 124.0\left(\mathrm{C}_{\mathrm{Ar}}\right), 126.4\left(\mathrm{CH}_{\mathrm{Ar}}\right), 127.7\left(\mathrm{C}_{\mathrm{Ar}}\right), 129.9\left(\mathrm{CH}_{\mathrm{Ar}}\right), 131.5\left(2 \mathrm{CH}_{\mathrm{Ar}}\right), 135.5\left(\mathrm{C}_{\mathrm{Ar}}\right), 136.8$ $\left(\mathrm{C}_{\text {Ar }}\right), 145.0\left(\mathrm{C}_{\mathrm{Ar}}\right), 145.3\left(\mathrm{C}_{\mathrm{Ar}}\right), 160.8\left(\mathrm{C}_{\mathrm{Ar}}\right)$ ppm. HRMS (ESI) $\mathrm{m} / z[\mathrm{M}+\mathrm{H}]^{+}$calcd. for $\left[\mathrm{C}_{16} \mathrm{H}_{15} \mathrm{~N}_{3} \mathrm{O}_{3} \mathrm{~S}\right]^{+}$: 330.0907; found 330.0907 .

3-[4-(4-Methoxyphenyl)-1-methyl-5-nitro-1H-imidazol-2-yl]pyridine (6j): Yield 69\% (75 mg); yellow solid; M.p. $152{ }^{\circ} \mathrm{C} .{ }^{1} \mathrm{H}-\mathrm{NMR}\left(\mathrm{CDCl}_{3}\right): \delta=3.86\left(\mathrm{~s}, 3 \mathrm{H}, \mathrm{NCH}_{3}\right), 4.01\left(\mathrm{~s}, 3 \mathrm{H}, \mathrm{OCH}_{3}\right), 6.98(\mathrm{~d}$, $\left.{ }^{3} J_{\mathrm{H}-\mathrm{H}}=9.0 \mathrm{~Hz}, 2 \mathrm{H}, 2 \mathrm{Ar}-\mathrm{H}\right), 7.48-7.53(\mathrm{~m}, 1 \mathrm{H}, \mathrm{Ar}-\mathrm{H}), 8.84\left(\mathrm{~d},{ }^{3} J_{\mathrm{H}-\mathrm{H}}=8.9 \mathrm{~Hz}, 2 \mathrm{H}, 2 \mathrm{Ar}-\mathrm{H}\right), 8.04-8.08$ $(\mathrm{m}, 1 \mathrm{H}, \mathrm{Ar}-\mathrm{H}), 8.79-8.80(\mathrm{~m}, 1 \mathrm{H}, \mathrm{Ar}-\mathrm{H}), 8.96(\mathrm{~s}, 1 \mathrm{H}, \mathrm{Ar}-\mathrm{H}) \mathrm{ppm} .{ }^{13} \mathrm{C}-\mathrm{NMR}\left(\mathrm{CDCl}_{3}\right): \delta=36.2\left(\mathrm{NCH}_{3}\right)$, $55.3\left(\mathrm{OCH}_{3}\right), 113.6\left(2 \mathrm{CH}_{\mathrm{Ar}}\right), 123.7\left(\mathrm{CH}_{\mathrm{Ar}}\right), 125.0\left(\mathrm{C}_{\mathrm{Ar}}\right), 131.3\left(2 \mathrm{CH}_{\mathrm{Ar}}\right), 135.9\left(\mathrm{C}_{\mathrm{Ar}}\right), 137.2\left(\mathrm{CH}_{\mathrm{Ar}}\right), 144.4$ $\left(\mathrm{C}_{\mathrm{Ar}}\right), 147.5\left(\mathrm{C}_{\mathrm{Ar}}\right), 149.9\left(\mathrm{CH}_{\mathrm{Ar}}\right), 151.4\left(\mathrm{CH}_{\mathrm{Ar}}\right), 160.8\left(2 \mathrm{C}_{\mathrm{Ar}}\right)$. HRMS (ESI) $m / z[\mathrm{M}+\mathrm{H}]^{+}$calcd. for $\left[\mathrm{C}_{16} \mathrm{H}_{14} \mathrm{~N}_{4} \mathrm{O}_{3}\right]^{+}$: 311.1139; found 311.1136.

2-(4-Methoxyphenyl)-1-methyl-5-nitro-4-phenyl-1H-imidazole (6): Yield 64\% (69 mg); yellow solid; M.p. $128{ }^{\circ} \mathrm{C} .{ }^{1} \mathrm{H}-\mathrm{NMR}\left(\mathrm{CDCl}_{3}\right): \delta=3.88\left(\mathrm{~s}, 3 \mathrm{H}, \mathrm{NCH}_{3}\right), 3.99\left(\mathrm{~s}, 3 \mathrm{H}, \mathrm{OCH}_{3}\right), 7.04\left(\mathrm{~d},{ }^{3} J_{\mathrm{H}-\mathrm{H}}=8.9 \mathrm{~Hz}, 2 \mathrm{H}\right.$, $2 \mathrm{Ar}-\mathrm{H}), 7.43-7.48(\mathrm{~m}, 3 \mathrm{H}, 3 \mathrm{Ar}-\mathrm{H}), 7.65\left(\mathrm{~d},{ }^{3} \mathrm{~J}_{\mathrm{H}-\mathrm{H}}=8.7 \mathrm{~Hz}, 2 \mathrm{H}, 2 \mathrm{Ar}-\mathrm{H}\right), 7.82-7.86(\mathrm{~m}, 2 \mathrm{H}, 2 \mathrm{Ar}-\mathrm{H}) \mathrm{ppm}$. ${ }^{13} \mathrm{C}-\mathrm{NMR}\left(\mathrm{CDCl}_{3}\right): \delta=36.1\left(\mathrm{NCH}_{3}\right), 55.5\left(\mathrm{OCH}_{3}\right), 114.6\left(2 \mathrm{CH}_{\mathrm{Ar}}\right), 121.0\left(\mathrm{C}_{\mathrm{Ar}}\right), 128.0\left(2 \mathrm{CH}_{\mathrm{Ar}}\right), 129.4$ 
$\left(\mathrm{CH}_{\mathrm{Ar}}\right), 129.7\left(2 \mathrm{CH}_{\mathrm{Ar}}\right), 131.3\left(2 \mathrm{CH}_{\mathrm{Ar}}\right), 132.1\left(\mathrm{C}_{\mathrm{Ar}}\right), 136.1\left(\mathrm{C}_{\mathrm{Ar}}\right), 144.2\left(\mathrm{C}_{\mathrm{Ar}}\right), 150.6\left(\mathrm{C}_{\mathrm{Ar}}\right), 161.7\left(\mathrm{C}_{\mathrm{Ar}}\right)$ ppm. Anal. Calcd. for $\mathrm{C}_{17} \mathrm{H}_{15} \mathrm{~N}_{3} \mathrm{O}_{3}$ (309.32): C 66.01, H 4.89, N 13.58; found C 65.98, H 4.75, N 13.42.

2,4-bis(4-methoxypheny)-1-methyl-5-nitro- $1 H$-imidazole (7): Yield 9\% using general procedure for the one-pot regioselective bis-Suzuki-Miyaura coupling reaction $(11 \mathrm{mg})$; yellow solid; M.p. 121 ${ }^{\circ} \mathrm{C} .{ }^{1} \mathrm{H}-\mathrm{NMR}\left(\mathrm{CDCl}_{3} 24{ }^{\circ} \mathrm{C}\right): \delta=3.86\left(\mathrm{~s}, 3 \mathrm{H}, \mathrm{NCH}_{3}\right), 3.89\left(\mathrm{~s}, 3 \mathrm{H}, \mathrm{OCH}_{3}\right), 3.97\left(\mathrm{~s}, 3 \mathrm{H}, \mathrm{OCH}_{3}\right), 6.98(\mathrm{~d}$, $\left.{ }^{3} J_{\mathrm{H}-\mathrm{H}}=7.6 \mathrm{~Hz}, 2 \mathrm{H}, 2 \mathrm{Ar}-\mathrm{H}\right), 7.02\left(\mathrm{~d},{ }^{3} J_{\mathrm{H}-\mathrm{H}}=8.1 \mathrm{~Hz}, 2 \mathrm{H}, 2 \mathrm{Ar}-\mathrm{H}\right), 7.65\left(\mathrm{~d},{ }^{3} J_{\mathrm{H}-\mathrm{H}}=7.9 \mathrm{~Hz}, 2 \mathrm{H}, 2 \mathrm{Ar}-\mathrm{H}\right)$, $7.86\left(\mathrm{~d},{ }^{3} J_{\mathrm{H}-\mathrm{H}}=7.6 \mathrm{~Hz}, 2 \mathrm{H}, 2 \mathrm{Ar}-\mathrm{H}\right) \mathrm{ppm} .{ }^{13} \mathrm{C}-\mathrm{NMR}\left(\mathrm{CDCl}_{3}\right): \delta=36.5\left(\mathrm{NCH}_{3}\right), 55.3\left(\mathrm{OCH}_{3}\right), 55.5$ $\left(\mathrm{OCH}_{3}\right), 113.6\left(2 \mathrm{CH}_{\mathrm{Ar}}\right), 114.5\left(2 \mathrm{CH}_{\mathrm{Ar}}\right), 120.5\left(\mathrm{C}_{\mathrm{Ar}}\right), 124.0\left(\mathrm{C}_{\mathrm{Ar}}\right), 131.3\left(2 \mathrm{CH}_{\mathrm{Ar}}\right), 131.5\left(2 \mathrm{CH}_{\mathrm{Ar}}\right), 135.6$ $\left(\mathrm{C}_{\mathrm{Ar}}\right), 144.5\left(\mathrm{C}_{\mathrm{Ar}}\right), 150.8\left(\mathrm{C}_{\mathrm{Ar}}\right), 160.8\left(\mathrm{C}_{\mathrm{Ar}}\right), 161.6\left(\mathrm{C}_{\mathrm{Ar}}\right) \mathrm{ppm}$. HRMS (ESI) $m / z[\mathrm{M}+\mathrm{H}]^{+}$calcd. for $\left[\mathrm{C}_{18} \mathrm{H}_{17} \mathrm{~N}_{3} \mathrm{O}_{4}\right]$ 340.1292; found 340.1292 .

3.2.4. General Procedure for the One-Pot Regioselective Suzuki-Miyaura/Sonogashira Coupling Reaction

A solution of 2,4-dibromo-1-methyl-5-nitro- $1 H$-imidazole $(2,0.1 \mathrm{~g}, 0.35 \mathrm{mmol}), 4$-methoxyphenylboronic acid (72 mg, $0.46 \mathrm{mmol}, 1.3$ equiv.), $\mathrm{Pd}(\mathrm{OAc})_{2}$ ( $3 \mathrm{mg}, 0.014 \mathrm{mmol}, 0.04$ equiv.), $\mathrm{Na}_{2} \mathrm{CO}_{3}$ ( $0.11 \mathrm{~g}, 1.05 \mathrm{mmol}, 3$ equiv.), in a DME $/ \mathrm{EtOH} / \mathrm{H}_{2} \mathrm{O}$ mixture $(3 / 1 / 1,5 \mathrm{~mL})$ was heated at $60^{\circ} \mathrm{C}$ under microwave irradiation for $2 \mathrm{~h}$. After cooling, terminal alkynes ( $0.45 \mathrm{mmol}, 1.3$ equiv.), $\mathrm{PPh}_{3}(9 \mathrm{mg}$, $0.035 \mathrm{mmol}, 0.1$ equiv.), $\mathrm{CuI}\left(7 \mathrm{mg}, 0.035 \mathrm{mmol}, 0.1\right.$ equiv.), $\mathrm{Et}_{3} \mathrm{~N}(0.1 \mathrm{~mL}, 0.7 \mathrm{mmol}, 2$ equiv.), were introduced under argon. The mixture was heated at $70^{\circ} \mathrm{C}$ for $1 \mathrm{~h}$ under microwave irradiation. After cooling, $60 \mathrm{~mL}$ of water were added and the solution was extracted with dichloromethane $(3 \times 50 \mathrm{~mL})$. The organic layer was washed with water $(3 \times 100 \mathrm{~mL})$, dried over $\mathrm{Na}_{2} \mathrm{SO}_{4}$ and evaporated. The crude product was purified by column chromatography [silica gel, petroleum ether/ethyl acetate $(10 \%),(50 \%$ for $8 \mathrm{~g}$ )] and recrystallized from propan-2-ol.

4-(4-Methoxyphenyl)-1-methyl-5-nitro-2-(phenylethynyl)-1H-imidazole (8a): Yield 67\% (78 mg); yellow solid; M.p. $156{ }^{\circ} \mathrm{C} .{ }^{1} \mathrm{H}-\mathrm{NMR}\left(\mathrm{CDCl}_{3}\right): \delta=3.87\left(\mathrm{~s}, 3 \mathrm{H}, \mathrm{NCH}_{3}\right), 4.14\left(\mathrm{~s}, 3 \mathrm{H}, \mathrm{OCH}_{3}\right), 6.97(\mathrm{~d}$, $\left.{ }^{3} J_{\mathrm{H}-\mathrm{H}}=8.0 \mathrm{~Hz}, 2 \mathrm{H}, 2 \mathrm{Ar}-\mathrm{H}\right), 7.39-7.51(\mathrm{~m}, 3 \mathrm{H}, 3 \mathrm{Ar}-\mathrm{H}), 7.64\left(\mathrm{~d},{ }^{3} J_{\mathrm{H}-\mathrm{H}}=6.6 \mathrm{~Hz}, 2 \mathrm{H}, 2 \mathrm{Ar}-\mathrm{H}\right), 8.82$ $\left(\mathrm{d},{ }^{3} J_{\mathrm{H}-\mathrm{H}}=8.8 \mathrm{~Hz}, 2 \mathrm{H}, 2 \mathrm{Ar}-\mathrm{H}\right) \mathrm{ppm} .{ }^{13} \mathrm{C}-\mathrm{NMR}\left(\mathrm{CDCl}_{3}\right): \delta=35.8\left(\mathrm{NCH}_{3}\right), 55.3\left(\mathrm{OCH}_{3}\right), 77.2(\mathrm{C})$, $96.5(\mathrm{C}), 113.5\left(2 \mathrm{CH}_{\mathrm{Ar}}\right), 120.3\left(\mathrm{C}_{\mathrm{Ar}}\right), 123.6\left(\mathrm{C}_{\mathrm{Ar}}\right), 128.7\left(2 \mathrm{CH}_{\mathrm{Ar}}\right), 130.3\left(\mathrm{CH}_{\mathrm{Ar}}\right), 131.2\left(2 \mathrm{CH}_{\mathrm{Ar}}\right), 132.2$ $\left(2 \mathrm{CH}_{\mathrm{Ar}}\right), 134.1\left(\mathrm{C}_{\mathrm{Ar}}\right), 134.4\left(\mathrm{C}_{\mathrm{Ar}}\right), 144.7\left(\mathrm{C}_{\mathrm{Ar}}\right), 160.8\left(\mathrm{C}_{\mathrm{Ar}}\right)$ ppm. Anal. Calcd. for $\mathrm{C}_{19} \mathrm{H}_{15} \mathrm{~N}_{3} \mathrm{O}_{3}(333.34)$ : C 68.46, H 4.54, N 12.61; found C 68.39, H 4.44, N 12.53.

4-(4-Methoxyphenyl)-1-methyl-5-nitro-2-(m-tolylethynyl)-1H-imidazole (8b): Yield 74\% $(90 \mathrm{mg})$; yellow solid; M.p. $138{ }^{\circ} \mathrm{C} .{ }^{1} \mathrm{H}-\mathrm{NMR}\left(\mathrm{CDCl}_{3}\right): \delta=2.56\left(\mathrm{~s}, 3 \mathrm{H}, \mathrm{CH}_{3}\right), 3.86\left(\mathrm{~s}, 3 \mathrm{H}, \mathrm{NCH}_{3}\right), 4.14(\mathrm{~s}$, $\left.3 \mathrm{H}, \mathrm{OCH}_{3}\right), 6.97\left(\mathrm{~d},{ }^{3} J_{\mathrm{H}-\mathrm{H}}=9.0 \mathrm{~Hz}, 2 \mathrm{H}, 2 \mathrm{Ar}-\mathrm{H}\right), 7.20-7.39(\mathrm{~m}, 3 \mathrm{H}, 3 \mathrm{Ar}-\mathrm{H}), 7.60\left(\mathrm{~d},{ }^{3} J_{\mathrm{H}-\mathrm{H}}=8.4 \mathrm{~Hz}, 1 \mathrm{H}\right.$, $\mathrm{Ar}-\mathrm{H}), 8.81\left(\mathrm{~d},{ }^{3} J_{\mathrm{H}-\mathrm{H}}=9.0 \mathrm{~Hz}, 2 \mathrm{H}, 2 \mathrm{Ar}-\mathrm{H}\right) \mathrm{ppm} .{ }^{13} \mathrm{C}-\mathrm{NMR}\left(\mathrm{CDCl}_{3}\right): \delta=20.9\left(\mathrm{CH}_{3}\right), 35.7\left(\mathrm{NCH}_{3}\right), 55.3$ $\left(\mathrm{OCH}_{3}\right), 81.0(\mathrm{C}), 95.6(\mathrm{C}), 113.5\left(2 \mathrm{CH}_{\mathrm{Ar}}\right), 120.2\left(\mathrm{C}_{\mathrm{Ar}}\right), 123.6\left(\mathrm{C}_{\mathrm{Ar}}\right), 126.0\left(\mathrm{CH}_{\mathrm{Ar}}\right), 129.8\left(\mathrm{CH}_{\mathrm{Ar}}\right), 130.3$ $\left(\mathrm{CH}_{\mathrm{Ar}}\right), 131.2\left(2 \mathrm{CH}_{\mathrm{Ar}}\right), 132.8\left(\mathrm{CH}_{\mathrm{Ar}}\right), 134.1\left(\mathrm{C}_{\mathrm{Ar}}\right), 134.6\left(\mathrm{C}_{\mathrm{Ar}}\right), 141.1\left(\mathrm{C}_{\mathrm{Ar}}\right), 144.7\left(\mathrm{C}_{\mathrm{Ar}}\right), 160.8\left(\mathrm{C}_{\mathrm{Ar}}\right) \mathrm{ppm}$. Anal. Calcd. for $\mathrm{C}_{20} \mathrm{H}_{17} \mathrm{~N}_{3} \mathrm{O}_{3}$ (347.37): C 69.15, H 4.93, N 12.10; found C 68.94, H 4.79, N 11.89.

2-[(3-Fluorophenyl)ethynyl]-4-(4-methoxyphenyl)-1-methyl-5-nitro-1H-imidazole (8c): Yield 59\% (73 mg); yellow solid; M.p. $148{ }^{\circ} \mathrm{C} .{ }^{1} \mathrm{H}-\mathrm{NMR}\left(\mathrm{CDCl}_{3}\right): \delta=3.86\left(\mathrm{~s}, 3 \mathrm{H}, \mathrm{NCH}_{3}\right), 4.13\left(\mathrm{~s}, 3 \mathrm{H}, \mathrm{OCH}_{3}\right)$, $6.97\left(\mathrm{~d},{ }^{3} J_{\mathrm{H}-\mathrm{H}}=8.8 \mathrm{~Hz}, 2 \mathrm{H}, 2 \mathrm{Ar}-\mathrm{H}\right), 7.13-7.21(\mathrm{~m}, 1 \mathrm{H}, \mathrm{Ar}-\mathrm{H}), 7.30-7.42(\mathrm{~m}, 3 \mathrm{H}, 3 \mathrm{Ar}-\mathrm{H}), 8.80(\mathrm{~d}$, $\left.{ }^{3} J_{\mathrm{H}-\mathrm{H}}=8.8 \mathrm{~Hz}, 2 \mathrm{H}, 2 \mathrm{Ar}-\mathrm{H}\right) \mathrm{ppm} .{ }^{13} \mathrm{C}-\mathrm{NMR}\left(\mathrm{CDCl}_{3}\right): \delta=35.9\left(\mathrm{NCH}_{3}\right), 55.3\left(\mathrm{OCH}_{3}\right), 77.9(\mathrm{C}), 94.8(\mathrm{~d}$, $\left.{ }^{4} J_{\mathrm{C}-\mathrm{F}}=3.2 \mathrm{~Hz}, \mathrm{C}\right), 113.5\left(2 \mathrm{CH}_{\mathrm{Ar}}\right), 117.7\left(\mathrm{~d},{ }^{2} J_{\mathrm{C}-\mathrm{F}}=21.1 \mathrm{~Hz}, \mathrm{CH}_{\mathrm{Ar}}\right), 119.0\left(\mathrm{~d},{ }^{2} J_{\mathrm{C}-\mathrm{F}}=23.9 \mathrm{~Hz}, \mathrm{CH}_{\mathrm{Ar}}\right)$, $122.1\left(\mathrm{~d},{ }^{3} J_{\mathrm{C}-\mathrm{F}}=9.7 \mathrm{~Hz}, \mathrm{C}_{\mathrm{Ar}}\right), 123.4\left(\mathrm{C}_{\mathrm{Ar}}\right), 128.1\left(\mathrm{~d},{ }^{4} J_{\mathrm{C}-\mathrm{F}}=3.2 \mathrm{~Hz}, \mathrm{CH}_{\mathrm{Ar}}\right), 130.4\left(\mathrm{~d},{ }^{3} J_{\mathrm{C}-\mathrm{F}}=8.7 \mathrm{~Hz}, \mathrm{CH}_{\mathrm{Ar}}\right)$, 131.2 $\left(2 \mathrm{CH}_{\mathrm{Ar}}\right), 133.9\left(\mathrm{C}_{\mathrm{Ar}}\right), 134.2\left(\mathrm{C}_{\mathrm{Ar}}\right), 144.6\left(\mathrm{C}_{\mathrm{Ar}}\right), 160.8\left(\mathrm{C}_{\mathrm{Ar}}\right), 162.2\left(\mathrm{~d},{ }^{1} J_{\mathrm{C}-\mathrm{F}}=248.2 \mathrm{~Hz}, \mathrm{C}_{\mathrm{Ar}}\right) \mathrm{ppm}$. Anal. Calcd. for $\mathrm{C}_{19} \mathrm{H}_{14} \mathrm{FN}_{3} \mathrm{O}_{3}$ (351.33): C 64.95, H 4.02, N 11.96; found C 64.67, H 3.84, N 11.79.

2-[(4-Methoxy-2-methylphenyl)ethynyl]-4-(4-methoxyphenyl)-1-methyl-5-nitro-1H-imidazole (8d): Yield 53\% (70 mg); yellow solid; M.p. $182{ }^{\circ} \mathrm{C} .{ }^{1} \mathrm{H}-\mathrm{NMR}\left(\mathrm{CDCl}_{3}\right): \delta=2.53\left(\mathrm{~s}, 3 \mathrm{H}, \mathrm{CH}_{3}\right), 3.84(\mathrm{~s}, 3 \mathrm{H}$, $\left.\mathrm{NCH}_{3}\right), 3.86\left(\mathrm{~s}, 3 \mathrm{H}, \mathrm{OCH}_{3}\right), 4.13\left(\mathrm{~s}, 3 \mathrm{H}, \mathrm{OCH}_{3}\right), 6.74-6.81(\mathrm{~m}, 2 \mathrm{H}, 2 \mathrm{Ar}-\mathrm{H}), 6.97\left(\mathrm{~d},{ }^{3} J_{\mathrm{H}-\mathrm{H}}=8.9 \mathrm{~Hz}, 2 \mathrm{H}, 2\right.$ 
Ar-H), $7.53\left(\mathrm{~d},{ }^{3} J_{\mathrm{H}-\mathrm{H}}=8.4 \mathrm{~Hz}, 1 \mathrm{H}, \mathrm{Ar}-\mathrm{H}\right), 7.81\left(\mathrm{~d},{ }^{3} J_{\mathrm{H}-\mathrm{H}}=8.9 \mathrm{~Hz}, 2 \mathrm{H}, 2 \mathrm{Ar}-\mathrm{H}\right) \mathrm{ppm} .{ }^{13} \mathrm{C}-\mathrm{NMR}\left(\mathrm{CDCl}_{3}\right)$ : $\delta=21.1\left(\mathrm{CH}_{3}\right), 35.7\left(\mathrm{NCH}_{3}\right), 55.3\left(\mathrm{OCH}_{3}\right), 55.4\left(\mathrm{OCH}_{3}\right), 80.1(\mathrm{C}), 96.2(\mathrm{C}), 111.8\left(\mathrm{CH}_{\mathrm{Ar}}\right), 112.3\left(\mathrm{C}_{\mathrm{Ar}}\right)$, $113.5\left(2 \mathrm{CH}_{\mathrm{Ar}}\right), 115.5\left(\mathrm{CH}_{\mathrm{Ar}}\right), 123.7\left(\mathrm{C}_{\mathrm{Ar}}\right), 131.3\left(2 \mathrm{CH}_{\mathrm{Ar}}\right), 134.0\left(\mathrm{C}_{\mathrm{Ar}}\right), 134.4\left(\mathrm{CH}_{\mathrm{Ar}}\right), 135.1\left(\mathrm{C}_{\mathrm{Ar}}\right), 143.2$ $\left(\mathrm{C}_{\mathrm{Ar}}\right), 144.8\left(\mathrm{C}_{\mathrm{Ar}}\right), 160.7\left(\mathrm{C}_{\mathrm{Ar}}\right), 161.1\left(\mathrm{C}_{\mathrm{Ar}}\right) \mathrm{ppm}$. Anal. Calcd. for $\mathrm{C}_{21} \mathrm{H}_{19} \mathrm{~N}_{3} \mathrm{O}_{4}$ (377.39): C 66.83, H 5.07, N 11.13; found C 66.56, H 4.91, N 11.10.

2-(Cyclopentylethynyl)-4-(4-methoxyphenyl)-1-methyl-5-nitro- $1 \mathrm{H}$-imidazole (8e): Yield 60\% (69 mg); yellow solid; M.p. $98{ }^{\circ} \mathrm{C} .{ }^{1} \mathrm{H}-\mathrm{NMR}\left(\mathrm{CDCl}_{3}\right): \delta=1.59-1.68\left(\mathrm{~m}, 2 \mathrm{H}, \mathrm{CH}_{2}\right), 1.73-1.82\left(\mathrm{~m}, 4 \mathrm{H}, 2 \mathrm{CH}_{2}\right)$, $2.00-2.10\left(\mathrm{~m}, 2 \mathrm{H}, \mathrm{CH}_{2}\right), 2.92\left(\mathrm{q},{ }^{3} J_{\mathrm{H}-\mathrm{H}}=7.5 \mathrm{~Hz}, 1 \mathrm{H}, \mathrm{CH}\right), 3.84\left(\mathrm{~s}, 3 \mathrm{H}, \mathrm{NCH}_{3}\right), 4.01\left(\mathrm{~s}, 3 \mathrm{H}, \mathrm{OCH}_{3}\right)$, $6.94\left(\mathrm{~d},{ }^{3} \mathrm{~J}_{\mathrm{H}-\mathrm{H}}=9.0 \mathrm{~Hz}, 2 \mathrm{H}, 2 \mathrm{Ar}-\mathrm{H}\right), 7.77\left(\mathrm{~d},{ }^{3} \mathrm{~J}_{\mathrm{H}-\mathrm{H}}=9.0 \mathrm{~Hz}, 2 \mathrm{H}, 2 \mathrm{Ar}-\mathrm{H}\right) \mathrm{ppm} .{ }^{13} \mathrm{C}-\mathrm{NMR}\left(\mathrm{CDCl}_{3}\right)$ : $\delta=25.2\left(2 \mathrm{CH}_{2}\right), 30.5(\mathrm{CH}), 33.4\left(2 \mathrm{CH}_{2}\right), 35.5\left(\mathrm{NCH}_{3}\right), 55.3\left(\mathrm{OCH}_{3}\right), 68.9(\mathrm{C}), 103.5(\mathrm{C}), 113.4\left(2 \mathrm{CH}_{\mathrm{Ar}}\right)$, $123.7\left(\mathrm{C}_{\mathrm{Ar}}\right), 131.2\left(2 \mathrm{CH}_{\mathrm{Ar}}\right), 133.6\left(\mathrm{C}_{\mathrm{Ar}}\right), 134.9\left(\mathrm{C}_{\mathrm{Ar}}\right), 144.4\left(\mathrm{C}_{\mathrm{Ar}}\right), 160.7\left(\mathrm{C}_{\mathrm{Ar}}\right) \mathrm{ppm}$. Anal. Calcd. for $\mathrm{C}_{18} \mathrm{H}_{19} \mathrm{~N}_{3} \mathrm{O}_{3}$ (325.36): C 66.45, H 5.89, N 12.91; found C 66.21, H 5.76, N 12.88.

2-[(4-tert-Butylphenyl)ethynyl]-4-(4-methoxyphenyl)-1-methyl-5-nitro-1 $\mathrm{H}$-imidazole (8f): Yield 63\% $(86 \mathrm{mg})$; yellow oil. ${ }^{1} \mathrm{H}-\mathrm{NMR}\left(\mathrm{CDCl}_{3}\right): \delta=1.34\left(\mathrm{~s}, 9 \mathrm{H}, 3 \mathrm{CH}_{3}\right), 3.86\left(\mathrm{~s}, 3 \mathrm{H}, \mathrm{NCH}_{3}\right), 4.12\left(\mathrm{~s}, 3 \mathrm{H}, \mathrm{OCH}_{3}\right)$, $6.96\left(\mathrm{~d},{ }^{3} J_{\mathrm{H}-\mathrm{H}}=8.8 \mathrm{~Hz}, 2 \mathrm{H}, 2 \mathrm{Ar}-\mathrm{H}\right), 7.43\left(\mathrm{~d},{ }^{3} J_{\mathrm{H}-\mathrm{H}}=8.4 \mathrm{~Hz}, 2 \mathrm{H}, 2 \mathrm{Ar}-\mathrm{H}\right), 7.56\left(\mathrm{~d},{ }^{3} J_{\mathrm{H}-\mathrm{H}}=8.4 \mathrm{~Hz}, 2 \mathrm{H}\right.$, $2 \mathrm{Ar}-\mathrm{H}), 7.81\left(\mathrm{~d},{ }^{3} \mathrm{~J}_{\mathrm{H}-\mathrm{H}}=8.8 \mathrm{~Hz}, 2 \mathrm{H}, 2 \mathrm{Ar}-\mathrm{H}\right) \mathrm{ppm} .{ }^{13} \mathrm{C}-\mathrm{NMR}\left(\mathrm{CDCl}_{3}\right): \delta=31.0\left(3 \mathrm{CH}_{3}\right), 35.0(\mathrm{C}), 35.7$ $\left(\mathrm{NCH}_{3}\right), 55.3\left(\mathrm{OCH}_{3}\right), 76.8(\mathrm{C}), 96.9(\mathrm{C}), 113.5\left(2 \mathrm{CH}_{\mathrm{Ar}}\right), 117.2\left(\mathrm{C}_{\mathrm{Ar}}\right), 123.6\left(\mathrm{C}_{\mathrm{Ar}}\right), 125.7\left(2 \mathrm{CH}_{\mathrm{Ar}}\right), 131.2$ $\left(2 \mathrm{CH}_{\mathrm{Ar}}\right), 132.0\left(2 \mathrm{CH}_{\mathrm{Ar}}\right), 134.0\left(\mathrm{C}_{\mathrm{Ar}}\right), 134.6\left(\mathrm{C}_{\mathrm{Ar}}\right), 144.7\left(\mathrm{C}_{\mathrm{Ar}}\right), 153.9\left(\mathrm{C}_{\mathrm{Ar}}\right), 160.7\left(\mathrm{C}_{\mathrm{Ar}}\right)$ ppm. HRMS (ESI) $m / z[\mathrm{M}+\mathrm{H}]^{+}$calcd. for $\left[\mathrm{C}_{23} \mathrm{H}_{23} \mathrm{~N}_{3} \mathrm{O}_{3}\right]^{+}: 390.1812$; found 390.1813 .

3-[4-(4-Methoxyphenyl)-1-methyl-5-nitro-1H-imidazol-2-yl]prop-2-yn-1-ol (8g): Yield 51\% (51 mg); yellow solid; M.p. $177^{\circ} \mathrm{C} .{ }^{1} \mathrm{H}-\mathrm{NMR}\left(\mathrm{DMSO}_{\mathrm{d}}\right): \delta=3.81\left(\mathrm{~s}, 3 \mathrm{H}, \mathrm{NCH}_{3}\right), 3.97\left(\mathrm{~s}, 3 \mathrm{H}, \mathrm{OCH}_{3}\right), 4.43(\mathrm{~d}$, $\left.{ }^{3} J_{\mathrm{H}-\mathrm{H}}=5.7 \mathrm{~Hz}, 2 \mathrm{H}, \mathrm{CH}_{2}\right), 5.67\left(\mathrm{t},{ }^{3} J_{\mathrm{H}-\mathrm{H}}=5.8 \mathrm{~Hz}, 1 \mathrm{H}, \mathrm{OH}\right), 7.01\left(\mathrm{~d},{ }^{3} J_{\mathrm{H}-\mathrm{H}}=8.8 \mathrm{~Hz}, 2 \mathrm{H}, 2 \mathrm{Ar}-\mathrm{H}\right), 7.67(\mathrm{~d}$, $\left.{ }^{3} J_{\mathrm{H}-\mathrm{H}}=8.8 \mathrm{~Hz}, 2 \mathrm{H}, 2 \mathrm{Ar}-\mathrm{H}\right) .{ }^{13} \mathrm{C}-\mathrm{NMR}\left(\mathrm{DMSO}_{\mathrm{d}}\right): \delta=35.9\left(\mathrm{NCH}_{3}\right), 49.8\left(\mathrm{CH}_{2}\right), 55.7\left(\mathrm{OCH}_{3}\right), 72.7(\mathrm{C})$, $97.5(\mathrm{C}), 113.9\left(2 \mathrm{CH}_{\mathrm{Ar}}\right), 124.1\left(\mathrm{C}_{\mathrm{Ar}}\right), 131.2\left(2 \mathrm{CH}_{\mathrm{Ar}}\right), 133.6\left(\mathrm{C}_{\mathrm{Ar}}\right), 134.5\left(\mathrm{C}_{\mathrm{Ar}}\right), 143.2\left(\mathrm{C}_{\mathrm{Ar}}\right), 160.6\left(\mathrm{C}_{\mathrm{Ar}}\right)$ ppm. Anal. Calcd. for $\mathrm{C}_{14} \mathrm{H}_{13} \mathrm{~N}_{3} \mathrm{O}_{4}$ (287.27): C 58.53, H 4.56, N 14.63; found C 58.64, H 4.51, N 14.40.

2-[(3-Chlorophenyl)ethynyl]-4-(4-methoxyphenyl)-1-methyl-5-nitro-1H-imidazole (8h): Yield 61\% (79 mg); yellow solid; M.p. $139{ }^{\circ} \mathrm{C} .{ }^{1} \mathrm{H}-\mathrm{NMR}\left(\mathrm{CDCl}_{3}\right): \delta=3.86\left(\mathrm{~s}, 3 \mathrm{H}, \mathrm{NCH}_{3}\right), 4.13\left(\mathrm{~s}, 3 \mathrm{H}, \mathrm{OCH}_{3}\right)$, $6.97\left(\mathrm{~d},{ }^{3} \mathrm{~J}_{\mathrm{H}-\mathrm{H}}=8.9 \mathrm{~Hz}, 2 \mathrm{H}, 2 \mathrm{Ar}-\mathrm{H}\right), 7.32-7.38(\mathrm{~m}, 1 \mathrm{H}, \mathrm{Ar}-\mathrm{H}), 7.42-7.47(\mathrm{~m}, 1 \mathrm{H}, \mathrm{Ar}-\mathrm{H}), 7.51(\mathrm{dt}$, $\left.{ }^{4} J_{\mathrm{H}-\mathrm{H}}=1.4 \mathrm{~Hz},{ }^{3} J_{\mathrm{H}-\mathrm{H}}=7.4 \mathrm{~Hz}, 1 \mathrm{H}, \mathrm{Ar}-\mathrm{H}\right), 7.61\left(\mathrm{t},{ }^{4} J_{\mathrm{H}-\mathrm{H}}=1.4 \mathrm{~Hz}, 1 \mathrm{H}, \mathrm{Ar}-\mathrm{H}\right), 8.80\left(\mathrm{~d},{ }^{3} J_{\mathrm{H}-\mathrm{H}}=8.9 \mathrm{~Hz}\right.$, 2H, $2 \mathrm{Ar}-\mathrm{H})$ ppm. ${ }^{13} \mathrm{C}-\mathrm{NMR}\left(\mathrm{CDCl}_{3}\right): \delta=35.8\left(\mathrm{NCH}_{3}\right), 55.3\left(\mathrm{OCH}_{3}\right), 78.2(\mathrm{C}), 94.7(\mathrm{C}), 113.6\left(2 \mathrm{CH}_{\mathrm{Ar}}\right)$, 122.0 $\left(\mathrm{C}_{\mathrm{Ar}}\right), 123.4\left(\mathrm{C}_{\mathrm{Ar}}\right), 130.0\left(\mathrm{CH}_{\mathrm{Ar}}\right), 130.3\left(\mathrm{CH}_{\mathrm{Ar}}\right), 130.6\left(\mathrm{CH}_{\mathrm{Ar}}\right), 131.2\left(2 \mathrm{CH}_{\mathrm{Ar}}\right), 131.9\left(\mathrm{CH}_{\mathrm{Ar}}\right), 133.8$ $\left(\mathrm{C}_{\mathrm{Ar}}\right), 134.2\left(\mathrm{C}_{\mathrm{Ar}}\right), 134.6\left(\mathrm{C}_{\mathrm{Ar}}\right), 144.6\left(\mathrm{C}_{\mathrm{Ar}}\right), 160.8\left(\mathrm{C}_{\mathrm{Ar}}\right)$. Anal. Calcd. for $\mathrm{C}_{19} \mathrm{H}_{14} \mathrm{ClN}_{3} \mathrm{O}_{3}$ (367.79): $\mathrm{C}$ 62.05, H 3.84, N 11.43; found C 61.90, H 3.77, N 11.35.

2-[(2-Chlorophenyl)ethynyl]-4-(4-methoxyphenyl)-1-methyl-5-nitro-1H-imidazole (8i): Yield 52\% $(67 \mathrm{mg})$; yellow solid; M.p. $171{ }^{\circ} \mathrm{C} .{ }^{1} \mathrm{H}-\mathrm{NMR}\left(\mathrm{CDCl}_{3}\right): \delta=3.87\left(\mathrm{~s}, 3 \mathrm{H}, \mathrm{NCH}_{3}\right), 4.19\left(\mathrm{~s}, 3 \mathrm{H}, \mathrm{OCH}_{3}\right)$, $6.98\left(\mathrm{~d},{ }^{3} J_{\mathrm{H}-\mathrm{H}}=8.5 \mathrm{~Hz}, 2 \mathrm{H}, 2 \mathrm{Ar}-\mathrm{H}\right), 7.29-7.42(\mathrm{~m}, 2 \mathrm{H}, 2 \mathrm{Ar}-\mathrm{H}), 7.49\left(\mathrm{~d},{ }^{3} J_{\mathrm{H}-\mathrm{H}}=7.9 \mathrm{~Hz}, 1 \mathrm{H}, \mathrm{Ar}-\mathrm{H}\right), 7.67$ $\left(\mathrm{d},{ }^{3} J_{\mathrm{H}-\mathrm{H}}=7.4 \mathrm{~Hz}, 1 \mathrm{H}, \mathrm{Ar}-\mathrm{H}\right), 7.80\left(\mathrm{~d},{ }^{3} J_{\mathrm{H}-\mathrm{H}}=8.7 \mathrm{~Hz}, 2 \mathrm{H}, 2 \mathrm{Ar}-\mathrm{H}\right) \mathrm{ppm} .{ }^{13} \mathrm{C}-\mathrm{NMR}\left(\mathrm{CDCl}_{3}\right): \delta=35.8$ $\left(\mathrm{NCH}_{3}\right), 55.3\left(\mathrm{OCH}_{3}\right), 82.1(\mathrm{C}), 92.8(\mathrm{C}), 113.6\left(2 \mathrm{CH}_{\mathrm{Ar}}\right), 120.7\left(\mathrm{C}_{\mathrm{Ar}}\right), 123.6\left(\mathrm{C}_{\mathrm{Ar}}\right), 126.9\left(\mathrm{CH}_{\mathrm{Ar}}\right), 129.6$ $\left(\mathrm{CH}_{\mathrm{Ar}}\right), 131.2\left(\mathrm{CH}_{\mathrm{Ar}}\right), 131.3\left(2 \mathrm{CH}_{\mathrm{Ar}}\right), 133.9\left(\mathrm{CH}_{\mathrm{Ar}}\right), 134.0\left(\mathrm{C}_{\mathrm{Ar}}\right), 134.1\left(\mathrm{C}_{\mathrm{Ar}}\right), 136.6\left(\mathrm{C}_{\mathrm{Ar}}\right), 144.6\left(\mathrm{C}_{\mathrm{Ar}}\right)$, $160.9\left(\mathrm{C}_{\mathrm{Ar}}\right) \mathrm{ppm}$. Anal. Calcd. for $\mathrm{C}_{19} \mathrm{H}_{14} \mathrm{ClN}_{3} \mathrm{O}_{3}$ (367.79): $\mathrm{C}$ 62.05, H 3.84, N 11.43; found C 61.86, H 3.66, N 11.31 .

2-(Cyclopropylethynyl)-4-(4-methoxyphenyl)-1-methyl-5-nitro-1H-imidazole (8j): Yield $63 \%$ (66 mg); yellow solid; M.p. $124{ }^{\circ} \mathrm{C} .{ }^{1} \mathrm{H}-\mathrm{NMR}\left(\mathrm{CDCl}_{3}\right): \delta=0.95-1.03\left(\mathrm{~m}, 4 \mathrm{H}, 2 \mathrm{CH}_{2}\right), 1.50-1.60(\mathrm{~m}, 1 \mathrm{H}, \mathrm{CH}), 3.85$ $\left(\mathrm{s}, 3 \mathrm{H}, \mathrm{NCH}_{3}\right), 4.02\left(\mathrm{~s}, 3 \mathrm{H}, \mathrm{OCH}_{3}\right), 6.94\left(\mathrm{~d},{ }^{3} J_{\mathrm{H}-\mathrm{H}}=8.8 \mathrm{~Hz}, 2 \mathrm{H}, 2 \mathrm{Ar}-\mathrm{H}\right), 7.77\left(\mathrm{~d},{ }^{3} J_{\mathrm{H}-\mathrm{H}}=8.9 \mathrm{~Hz}, 2 \mathrm{H}\right.$, $2 \mathrm{Ar}-\mathrm{H})$ ppm. ${ }^{13} \mathrm{C}-\mathrm{NMR}\left(\mathrm{CDCl}_{3}\right): \delta=0.2(\mathrm{CH}), 9.3\left(2 \mathrm{CH}_{2}\right), 35.5\left(\mathrm{NCH}_{3}\right), 55.3\left(\mathrm{OCH}_{3}\right), 64.4(\mathrm{C}), 77.2$ (C), $102.4\left(\mathrm{C}_{\mathrm{Ar}}\right), 113.5\left(2 \mathrm{CH}_{\mathrm{Ar}}\right), 123.7\left(\mathrm{C}_{\mathrm{Ar}}\right), 131.3\left(2 \mathrm{CH}_{\mathrm{Ar}}\right), 134.7\left(\mathrm{C}_{\mathrm{Ar}}\right), 144.3\left(\mathrm{C}_{\mathrm{Ar}}\right), 160.8\left(\mathrm{C}_{\mathrm{Ar}}\right) \mathrm{ppm}$. Anal. Calcd. for $\mathrm{C}_{16} \mathrm{H}_{15} \mathrm{~N}_{3} \mathrm{O}_{3}$ (297.31): C 64.64, H 5.09, N 14.13; found C 64.46, H 4.92, N 14.22. 
1-Methyl-5-nitro-2,4-bis(phenylethynyl)-1H-imidazole (9): Yield 10\% using general procedure for the one-pot regioselective Suzuki-Miyaura/Sonogashira coupling reaction (12 mg); yellow solid; M.p. $166{ }^{\circ} \mathrm{C} .{ }^{1} \mathrm{H}-\mathrm{NMR}\left(\mathrm{CDCl}_{3}\right): \delta=4.14\left(\mathrm{~s}, 3 \mathrm{H}, \mathrm{NCH}_{3}\right), 7.38-7.48(\mathrm{~m}, 6 \mathrm{H}, 6 \mathrm{Ar}-\mathrm{H}), 7.61-7.66(\mathrm{~m}, 4 \mathrm{H}, 4$ Ar-H) ppm. ${ }^{13} \mathrm{C}-\mathrm{NMR}\left(\mathrm{CDCl}_{3}\right): \delta=35.6\left(\mathrm{NCH}_{3}\right), 76.7(\mathrm{C}), 81.0(\mathrm{C}), 96.8(\mathrm{C}), 97.1(\mathrm{C}), 120.0\left(\mathrm{C}_{\mathrm{Ar}}\right), 121.7$ $\left(\mathrm{C}_{\mathrm{Ar}}\right), 127.7\left(\mathrm{C}_{\mathrm{Ar}}\right), 128.5\left(2 \mathrm{CH}_{\mathrm{Ar}}\right), 128.7\left(2 \mathrm{CH}_{\mathrm{Ar}}\right), 129.6\left(\mathrm{CH}_{\mathrm{Ar}}\right), 130.5\left(\mathrm{CH}_{\mathrm{Ar}}\right), 132.2\left(2 \mathrm{CH}_{\mathrm{Ar}}\right), 132.3(2$ $\left.\mathrm{CH}_{\text {Ar }}\right), 133.5\left(\mathrm{C}_{\text {Ar }}\right), 135.1\left(\mathrm{C}_{\text {Ar }}\right)$ ppm. HRMS (ESI) $m / z[\mathrm{M}+\mathrm{H}]^{+}$calcd. for $\left[\mathrm{C}_{20} \mathrm{H}_{13} \mathrm{~N}_{3} \mathrm{O}_{2}\right]^{+}: 328.1081$; found 328.1081 .

Figures S1-S66: ${ }^{1} \mathrm{H}$ - and ${ }^{13} \mathrm{C}-\mathrm{NMR}$ of all compounds $\mathbf{3 a} \mathbf{a}-\mathbf{i}, \mathbf{5}, \mathbf{6 a - j}, \mathbf{6}, \mathbf{7}, \mathbf{8} \mathbf{a}-\mathbf{j}$ and $\mathbf{9}$.

\subsubsection{Crystal Data for Compound 3c}

$2\left(\mathrm{C}_{11} \mathrm{H}_{7} \mathrm{BrF}_{3} \mathrm{~N}_{3} \mathrm{O}_{2}\right), M=700.21, a=8.4376(4) \AA, b=12.5416(6) \AA, c=12.6319(5) \AA, \alpha=82.406(4)^{\circ}$, $\beta=73.324(4)^{\circ}, \gamma=80.384(4)^{\circ}, V=1257.48(10) \AA^{3}, T=293 \mathrm{~K}$, space group $P \overline{1} Z=2,14503$ reflections measured, 5058 independent reflections $\left(R_{\text {int }}=0.0184\right)$. The final $R_{1}$ values were $0.0320(I>2 \sigma(I))$. The final $w R\left(F^{2}\right)$ values were $0.0689(I>2 \sigma(I))$. The final $R_{1}$ values were 0.0469 (all data). The final $w R\left(F^{2}\right)$ values were 0.0752 (all data). The goodness of fit on $F^{2}$ was 1.007. CCDC 1542022 contains the supplementary crystallographic data for this paper. These data can be obtained free of charge at www.cdcc.cam.ac.uk/data_request/cif of from the Cambridge Crystallographic Data Centre, 12, Union Road, Cambridge CB2 1EZ, UK; Fax: + 44 (1223) 336033; email: deposit@ccdc.cam.ac.uk.

\subsection{Biology}

\subsubsection{In Vitro Antibacterial Activity}

Bacterial strains: the bacteria tested were obtained from the bacteriology laboratory of IHU Mediterranée Infection (Marseille, France). Each bacterium was cultured in anaerobic condition on $5 \%$ sheep blood-enriched Columbia agar (Biomérieux, Marcy l'Etoile, France), incubated at $37^{\circ} \mathrm{C}$ for $48 \mathrm{~h}$. The derivatives were dissolved in DMSO stock solution: $500 \mu \mathrm{g} / \mathrm{mL}$. Thereafter, in a sterile medium and in a logarithmic growth phase, a concentration of $1 \mathrm{McFarland}\left(3.10^{8} \mathrm{CFU} / \mathrm{mL}\right)$ was obtained using a spectrophotometer. First, in the 5\% sheep blood-enriched Columbia agar medium, the superficial bacterial culture was performed with a swab impregnated with the bacterial suspension. Then, $10 \mu \mathrm{L}$ of each derivative were deposited on blank sterile discs. For the negative control, the DMSO-impregnated disc was used. After $48 \mathrm{~h}$ of incubation, the growth inhibition zone diameter was measured.

\subsubsection{In Vitro Antiparasitic Activity}

For Trichomonas vaginalis the MIC was carried out in a sterile 96-well plate by broth microdilution according to EUCAST guidelines, and using LYI medium. First, $190 \mu \mathrm{L}$ of the LYI broth medium, was added to each well. Then, $10 \mu \mathrm{L}$ of each imidazole derivative with the primary concentration $200 \mu \mathrm{g} / \mathrm{mL}$ was added to the first wells. After mixing, $100 \mu \mathrm{L}$ of this mixture was embedded into the second well. A similar dilution procedure was carried out in the first wells line for metronidazole as control group. $100 \mu \mathrm{L}$ of the trichomonas suspension $\left(10^{5} \mathrm{cells} / \mathrm{mL}\right)$ was added to each well. For negative control, $200 \mu \mathrm{L}$ of LYI broth medium were added to the border wells. The plates were incubated under anaerobic conditions $24 \mathrm{~h}$ at $37^{\circ} \mathrm{C}$.

\subsubsection{In Vitro Cytotoxicity Evaluation}

Principle of the Assay

The NRU toxicity test is based on concentration-dependent reduction of the uptake of the vital dye Neutral Red measured $24 \mathrm{~h}$ after chemical treatment. Neutral red is a weak cationic dye that readily penetrates cell membranes by non-diffusion, accumulating intracellularly in lysosomes. Alterations of the cell surface or the sensitive lysosomal membrane lead to lysosomal fragility and other changes that 
gradually become irreversible. Such changes brought about by the action of xenobiotics result in a decreased uptake and binding of NR in non-viable cells.

Cell Line

CHO-K1 Chinese Hamster Ovary cells (ATCC CCL61), low passage number $(<50)$.

\section{Culture Medium}

Mc Coy's medium supplemented with penicillin $100 \mathrm{UI} / \mathrm{mL}$ and steptomycin $100 \mu \mathrm{g} / \mathrm{mL}$, and $10 \%$ of inactivated calf serum, $\mathrm{pH} 7.2$, freshly prepared, stored no longer than 1 week.

\section{Test Procedure}

Cells were seeded into two 96 -well tissue culture plates ( $0.1 \mathrm{~mL}$ per well), at a concentration of $1.10^{5}$ cells $/ \mathrm{mL}$, and incubated at $37^{\circ} \mathrm{C}\left(5 \% \mathrm{CO}_{2}\right)$ for $24 \mathrm{~h}$ until confluent. The culture medium was decanted and replaced by $100 \mu \mathrm{L}$ of fresh medium containing the appropriate concentrations of the test substances (8 different concentrations in triplicate), then cells were incubated at $37^{\circ} \mathrm{C}\left(5 \% \mathrm{CO}_{2}\right)$ in the dark for $24 \mathrm{~h}$. At the end of the incubation period, cells were washed, placed into Neutral Red medium $\left(50 \mu \mathrm{g} / \mathrm{mL}\right.$ Neutral Red in complete medium) and incubated for $3 \mathrm{~h}$ at $37^{\circ} \mathrm{C}, 5 \% \mathrm{CO}_{2}$. Then, the medium was removed and cells were washed three times with $0.2 \mathrm{~mL}$ of PBS to remove excess dye. The Neutral Red medium was removed and the distaining solution (50\% ethanol, $1 \%$ acetic acid, $49 \%$ distilled water; $50 \mu \mathrm{L}$ per well) was added into the wells. Then, the plates were shaken for 15-20 min at room temperature in the dark. The degree of membrane damage (i.e., the increase of released Neutral Red) was measured by a fluorescence-luminescence reader. The Optical Density (OD) of each well was read at $540 \mathrm{~nm}$. The results obtained for wells treated with the test material were compared to those of untreated control wells ( $100 \%$ viability) and converted to percentage values.

\section{Calculation of $\mathrm{CC}_{50}$}

The mean OD value of blank wells (containing only Neutral Red desorbed solution) was subtracted from the mean OD value of three treated wells (dilutions of the test material, positive control or HBSS). The percentages of cell viability were calculated as:

$$
\begin{aligned}
& \text { (Mean OD of test wells }- \text { mean OD of blanks) } \times 100 \\
& \text { Mean OD of negative control }- \text { mean OD of blanks }
\end{aligned}
$$

The concentration of the test substances causing a 50\% release of Neutral Red as compared to the control culture was calculated by non-linear regression analysis using the Phototox Version 2.0 software (Zebet, Berlin, Germany).

\section{Conclusions}

In summary, we describe here a novel and efficient method to access 2,4-disubstituted 5-nitro-imidazole derivatives under microwave irradiation. We have developed original one-pot regioselective bis-Suzuki-Miyaura or Suzuki-Miyaura/Sonogashira reactions of 2,4-dibromo1-methyl-5-nitro-1 $\mathrm{H}$-imidazole (2) allowing the functionalization at both C-2 and C-4 positions of this scaffold. Moreover, this method tolerates a wide range of boronic acids and terminal alkynes and provides versatile and rapid access to 2,4-disubstituted 5-nitroimidazole derivatives in moderate to good yields. The synthesized products were tested for their antimicrobial activities and compared with the standard metronidazole. Compounds obtained with the regioselective Suzuki-Miyaura reaction, bearing a bromine in 2-position and aryl or hetero aryl group in 4-position (compounds $\mathbf{3 b}, \mathbf{3} \mathbf{e}-\mathbf{i}$ ), showed an equivalent activity to metronidazole against anaerobic bacteria, and higher activity against T. vaginalis. 
Supplementary Materials: Supplementary Materials are available online. Figures S1-S66: ${ }^{1} \mathrm{H}-$ and ${ }^{13} \mathrm{C}-\mathrm{NMR}$ of all compounds $3 \mathbf{a}-\mathbf{i}, \mathbf{5}, \mathbf{6 a}-\mathbf{j}, \mathbf{6}, \mathbf{7}, \mathbf{8 a - j}$ and $\mathbf{9}$.

Acknowledgments: This work was supported by the CNRS (Centre National de la Recherche Scientifique) and Aix-Marseille Université. The authors thank V. Remusat for NMR spectra recording and the Spectropole team for various analytical measurements.

Author Contributions: F.M. and Y.K. conceived and designed the experiments; F.M., Y.K., C.S., L.O. and C.D. performed the experiments; F.M., Y.K., C.S, L.O., C.D., J.-M.R., M.D.C. and P.V. discussed the results. F.M., Y.K., L.O., C.D., J.-M.R., M.D.C. and P.V. wrote the paper.

Conflicts of Interest: The authors declare no conflict of interest.

\section{References}

1. Citron, D.M.; Tyrrell, K.L.; Warren, Y.A.; Fernandez, H.; Merriam, C.V.; Goldstein, E.J.C. In vitro activities of tinidazole and metronidazole against Clostridium difficile, Prevotella bivia and Bacteroides fragilis. Anaerobe 2005, 11, 315-317. [CrossRef] [PubMed]

2. Ravdin, J.I. Amebiasis. Clin. Infect. Dis. 1995, 20, 1453-1466. [CrossRef] [PubMed]

3. Kim, P.; Kang, S.; Boshoff, H.I.; Jiricek, J.; Collins, M.; Singh, R.; Manjunatha, U.H.; Niyomrattanakit, P.; Zhang, L.; Goodwin, M.; et al. Structure-Activity Relationships of Antitubercular Nitroimidazoles. 2. Determinants of Aerobic Activity and Quantitative Structure-Activity Relationships. J. Med. Chem. 2009, 52, 1329-1344. [CrossRef] [PubMed]

4. Leitsch, D.; Kolarich, D.; Wilson, I.B.H.; Altmann, F.; Duchêne, M. Nitroimidazole Action in Entamoeba histolytica: A Central Role for Thioredoxin Reductase. PLoS Biol. 2007, 5, e211. [CrossRef] [PubMed]

5. Löfmark, S.; Edlund, C.; Nord, C.E. Metronidazole is still the drug of choice for treatment of anaerobic infections. Clin. Infect. Dis. 2010, 50, S16-S23. [CrossRef] [PubMed]

6. Duan, Y.-T.; Yao, Y.-F.; Huang, W.; Makawana, J.A.; Teraiya, S.B.; Thumar, N.J.; Tang, D.-J.; Tao, X.-X.; Wang, Z.-C.; Jiang, A.-Q.; et al. Synthesis, biological evaluation, and molecular docking studies of novel 2-styryl-5-nitroimidazole derivatives containing 1,4-benzodioxan moiety as FAK inhibitors with anticancer activity. Bioorg. Med. Chem. 2014, 22, 2947-2954. [CrossRef] [PubMed]

7. Leitsch, D. Recent Advances in the Trichomonas vaginalis Field. F1000Research 2016, 5, 162-169. [CrossRef] [PubMed]

8. Sisson, G.; Goodwin, A.; Raudonikiene, A.; Hughes, N.J.; Mukhopadhyay, A.K.; Berg, D.E.; Hoffman, P.S. Enzymes Associated with Reductive Activation and Action of Nitazoxanide, Nitrofurans, and Metronidazole in Helicobacter pylori. Antimicrob. Agents Chemother. 2002, 46, 2116-2123. [CrossRef] [PubMed]

9. Kulda, J. Trichomonads, hydrogenosomes and drug resistance. Int. J. Parasitol. 1999, 29, 199-212. [CrossRef]

10. Pal, D.; Banerjee, S.; Cui, J.; Schwartz, A.; Ghosh, S.K.; Samuelson, J. Giardia, Entamoeba, and Trichomonas Enzymes Activate Metronidazole (Nitroreductases) and Inactivate Metronidazole (Nitroimidazole Reductases). Antimicrob. Agents Chemother. 2009, 53, 458-464. [CrossRef] [PubMed]

11. Leitsch, D.; Kolarich, D.; Binder, M.; Stadlmann, J.; Altmann, F.; Duchêne, M. Trichomonas vaginalis: metronidazole and other nitroimidazole drugs are reduced by the flavin enzyme thioredoxin reductase and disrupt the cellular redox system. Implications for nitroimidazole toxicity and resistance. Mol. Microbiol. 2009, 72, 518-536. [CrossRef] [PubMed]

12. Upcroft, P.; Upcroft, J.A. Drug Targets and mechanisms of resistance in the anaerobic protozoa. Clin. Microbiol. Rev. 2001, 14, 150-164. [CrossRef] [PubMed]

13. Land, K.M.L.; Clemens, D.L.; Johnson, P.J. Loss of multiple hydrogenosomal proteins associated with organelle metabolism and high-Level drug resistance in trichomonads. Exp. Parasitol. 2001, 97, 102-110. [CrossRef] [PubMed]

14. Hrdy, I.; Cammack, R.; Stopka, P.; Kulda, J.; Tachezy, J. Alternative pathway of metronidazole activation in Trichomonas vaginalis hydrogenosomes. Antimicrob. Agents Chemother. 2005, 49, 5033-5036. [CrossRef] [PubMed]

15. Leitsch, D.; Drinić, M.; Kolarich, D.; Duchêne, M. Down-regulation of flavin reductase and alcohol dehydrogenase-1 (ADH1) in metronidazole-resistant isolates of Trichomonas vaginalis. Mol. Biochem. Parasitol. 2012, 183, 177-183. [CrossRef] [PubMed] 
16. Lemée, V.; Zaharia, I.; Nevez, G.; Rabodonirina, M.; Brasseur, P.; Ballet, J.J.; Favennec, L. Metronidazole and albendazole susceptibility of 11 clinical isolates of Giardia duodenalis from France. J. Antimicrob. Chemother. 2000, 46, 819-821. [CrossRef] [PubMed]

17. Solaymani-Mohammadi, S.; Genkinger, J.M.; Loffredo, C.A.; Singer, S.M. A meta-analysis of the effectiveness of albendazole compared with metronidazole as treatments for infections with Giardia duodenalis. PLoS Negl. Trop. Dis. 2010, 4, e682. [CrossRef] [PubMed]

18. Nabarro, L.E.B.; Lever, R.A.; Armstrong, M.; Chiodini, P.L. Increased incidence of nitroimidazole-refractory giardiasis at the Hospital for Tropical Diseases, London: 2008-2013. Clin. Microbiol. Infect. 2015, 21, 791-796. [CrossRef] [PubMed]

19. Breuil, J.; Dublanchet, A.; Truffaut, N.; Sebald, M. Transferable 5-nitroimidazole resistance in the Bacteroides fragilis group. Plasmid 1989, 21, 151-154. [CrossRef]

20. Tomb, J.-F.; White, O.; Kerlavage, A.R.; Clayton, R.A.; Sutton, G.G.; Fleischmann, R.D.; Ketchum, K.A.; Klenk, H.P.; Gill, S.; Dougherty, B.A.; et al. The complete genome sequence of the gastric pathogen Helicobacter pylori. Nature 1997, 388, 539-547. [CrossRef] [PubMed]

21. Schapiro, J.M.; Gupta, R.; Stefansson, E.; Fang, F.C.; Limaye, A.P. Isolation of metronidazole-resistant Bacteroides fragilis carrying the nima nitroreductase gene from a patient in washington state. J. Clin. Microbiol. 2004, 42, 4127-4129. [CrossRef] [PubMed]

22. Graham, D.Y.; Fischbach, L. Helicobacter pylori treatment in the era of increasing antibiotic resistance. Gut 2010, 59, 1143-1153. [CrossRef] [PubMed]

23. Secka, O.; Berg, D.E.; Antonio, M.; Corrah, T.; Tapgun, M.; Walton, R.; Thomas, V.; Galano, J.J.; Sancho, J.; Adegbola, R.A.; et al. Antimicrobial susceptibility and resistance patterns among Helicobacter pylori strains from the Gambia, West Africa. Antimicrob. Agents Chemother. 2013, 57, 1231-1237. [CrossRef] [PubMed]

24. Lossick, J.G.; Müller, M.; Gorrell, T.E. In vitro drug susceptibility and doses of metronidazole required for cure in cases of refractory vaginal trichomoniasis. J. Infect. Dis. 1986, 153, 948-955. [CrossRef] [PubMed]

25. Gardner, T.B.; Hill, D.R. Treatment of Giardiasis. Clin. Microbiol. Rev. 2001, 14, 114-128. [CrossRef] [PubMed]

26. Lindmark, D.G.; Müller, M. Antitrichomonad action, mutagenicity, and reduction of metronidazole and other nitroimidazoles. Antimicrob. Agents Chemother. 1976, 10, 476-482. [CrossRef] [PubMed]

27. Voogd, C.E. On the mutagenicity of nitroimidazoles. Mutat. Res. Genet. Toxicol. 1981, 86, 243-277. [CrossRef]

28. De Méo, M.; Vanelle, P.; Bernadini, E.; Laget, M.; Maldonado, J.; Jentzer, O.; Crozet, M.P.; Duménil, G. Evaluation of the mutagenic and genotoxic activities of 48 nitroimidazoles and related imidazole derivatives by the Ames test and the SOS Chromotest. Environ. Mol. Mutagen. 1992, 19, 167-181. [CrossRef] [PubMed]

29. Ré, J.L.; De Méo, M.; Laget, M.; Guiraud, H.; Castegnaro, M.; Vanelle, P.; Duménil, G. Evaluation of the genotoxic activity of metronidazole and dimetridazole in human lymphocytes by the comet assay. Mutat. Res. Mol. Mech. Mutagen. 1997, 375, 147-155. [CrossRef]

30. Trinh, S.; Reysset, G. Mutagenic action of 5-nitroimidazoles: in vivo induction of GC $\rightarrow$ CG transversion in two Bacteroides fragilis reporter genes. Mutat. Res. Mol. Mech. Mutagen. 1998, 398, 55-65. [CrossRef]

31. Upcroft, J.A.; Dunn, L.A.; Wright, J.M.; Benakli, K.; Upcroft, P.; Vanelle, P. 5-Nitroimidazole drugs effective against metronidazole-resistant Trichomonas vaginalis and Giardia duodenalis. Antimicrob. Agents Chemother. 2006, 50, 344-347. [CrossRef] [PubMed]

32. Falagas, M.E.; Walker, A.M.; Jick, H.; Ruthazer, R.; Griffith, J.; Snydman, D.R. Late incidence of cancer after metronidazole use: A matched metronidazole user/nonuser study. Clin. Infect. Dis. 1998, 26, 384-388. [CrossRef] [PubMed]

33. Ferraris, L.; Schönherr, S.; Bouvet, P.; Dauphin, B.; Popoff, M.; Butel, M.J.; Aires, J. One-Step Multiplex PCR assay for differentiating proposed new species "clostridium neonatale" from closely related species. J. Clin. Microbiol. 2015, 53, 3621-3623. [CrossRef] [PubMed]

34. Cassir, N.; Benamar, S.; La Scola, B. Clostridium butyricum: From beneficial to a new emerging pathogen. Clin. Microbiol. Infect. 2016, 22, 37-45. [CrossRef] [PubMed]

35. Aljarallah, K.M. Conventional and alternative treatment approaches for Clostridium difficile infection. Int. J. Health Sci. 2017, 11, 1-10.

36. Olivo, G.; Lucas, T.M.; Borges, A.S.; Silva, R.O.S.; Lobato, F.C.F.; Siqueira, A.K.; Da Silva Leite, D.; Brandão, P.E.; Gregori, F.; De Oliveira-Filho, J.P.; et al. Enteric pathogens and coinfections in foals with and without diarrhea. Biomed Res. Int. 2016, 2016, 1-12. [CrossRef] [PubMed] 
37. Crozet, M.P.; Surzur, J.-M.; Vanelle, P.; Ghiglione, C.; Maldonado, J. $\mathrm{S}_{\mathrm{RN}} 1$ reactions of heterocyclic compounds. II. Reactivity of 1-methyl-2-chloromethyl-5-nitroimidazole. Tetrahedron Lett. 1985, 26, 1023-1026. [CrossRef]

38. Vanelle, P.; Maldonado, J.; Crozet, M.; Senouki, K.; Delmas, F.; Gasquet, M.; Timon-David, P. Preparation and antiparasitic activity of new imidazoles bearing dioxane or hexahydropyrimidine moiety. Eur. J. Med. Chem. 1991, 26, 709-714. [CrossRef]

39. Jentzer, O.; Vanelle, P.; Crozet, M.; Maldonado, J.; Barreau, M. New highly active 5-nitroimidazoles bearing lactam nuclei: Synthesis and antibacterial properties. Eur. J. Med. Chem. 1991, 26, 687-697. [CrossRef]

40. Vanelle, P.; Benakli, K.; Maldonado, J.; Crozet, M.P. An electron-transfer reaction in the imidazo[2,1- $b$ ]thiazole series. Heterocycles 1998, 48, 181-185. [CrossRef]

41. Upcroft, J.A.; Campbell, R.W.; Benakli, K.; Upcroft, P.; Vanelle, P. Efficacy of new 5-nitroimidazoles against metronidazole-susceptible and -resistant Giardia, Trichomonas, and Entamoeba spp. Antimicrob. Agents Chemother. 1999, 43, 73-76. [PubMed]

42. Chauvière, G.; Viodé, C.; Périé, J. Nucleophilic substitution studies on nitroimidazoles, and applications to the synthesis of biologically active compounds. J. Heterocycl. Chem. 2000, 37, 119-126. [CrossRef]

43. Benakli, K.; Terme, T.; Vanelle, P. Synthesis of new active sulfones in the 5-nitroimidazole series. Molecules 2002, 7, 382-385. [CrossRef]

44. Valdez, C.A.; Tripp, J.C.; Miyamoto, Y.; Kalisiak, J.; Hruz, P.; Andersen, Y.S.; Brown, S.E.; Kangas, K.; Arzu, L.V.; Davids, B.J.; et al. Synthesis and electrochemistry of 2-ethenyl and 2-ethanyl derivatives of 5-nitroimidazole and antimicrobial activity against Giardia lamblia. J. Med. Chem. 2009, 52, 4038-4053. [CrossRef] [PubMed]

45. Crozet, M.D.; Botta, C.; Gasquet, M.; Curti, C.; Rémusat, V.; Hutter, S.; Chapelle, O.; Azas, N.; De Méo, M.; Vanelle, P. Lowering of 5-nitroimidazole's mutagenicity: towards optimal antiparasitic pharmacophore. Eur. J. Med. Chem. 2009, 44, 653-659. [CrossRef] [PubMed]

46. Dunn, L.A.; Burgess, A.G.; Krauer, K.G.; Eckmann, L.; Vanelle, P.; Crozet, M.D.; Gillin, F.D.; Upcroft, P.; Upcroft, J.A. A new-generation 5-nitroimidazole can induce highly metronidazole-resistant Giardia lamblia in vitro. Int. J. Antimicrob. Agents 2010, 36, 37-42. [CrossRef] [PubMed]

47. Miyamoto, Y.; Kalisiak, J.; Korthals, K.; Lauwaet, T.; Cheung, D.Y.; Lozano, R.; Cobo, E.R.; Upcroft, P.; Upcroft, J.A.; Berg, D.E.; et al. Expanded therapeutic potential in activity space of next-generation 5-nitroimidazole antimicrobials with broad structural diversity. Proc. Natl. Acad. Sci. USA 2013, 110, 17564-17569. [CrossRef] [PubMed]

48. Neildé, K.; Crozet, M.D.; Terme, T.; Vanelle, P. First single electron transfer reaction on propargylic chloride in 5-nitroimidazole series. Tetrahedron Lett. 2014, 55, 3652-3657. [CrossRef]

49. Walsh, J.S.; Wang, R.; Bagan, E.; Wang, C.C.; Wislocki, P.; Miwa, G.T. Structural alterations that differentially affect the mutagenic and antitrichomonal activities of 5-nitroimidazoles. J. Med. Chem. 1987, 30, 150-156. [CrossRef] [PubMed]

50. Crozet, M.; Terme, T.; Vanelle, P. Designing new 5-nitroimidazoles: Towards safer anti-infectious agents. Lett. Drug Des. Discov. 2013, 11, 531-559. [CrossRef]

51. Magano, J.; Dunetz, J.R. Large-scale applications of transition metal-catalyzed couplings for the synthesis of pharmaceuticals. Chem. Rev. 2011, 111, 2177-2250. [CrossRef] [PubMed]

52. Johansson Seechurn, C.C.C.; Kitching, M.O.; Colacot, T.J.; Snieckus, V. Palladium-catalyzed cross-coupling: A historical contextual perspective to the 2010 Nobel Prize. Angew. Chem. Int. Ed. 2012, 51, 5062-5085. [CrossRef] [PubMed]

53. Schröter, S.; Stock, C.; Bach, T. Regioselective cross-coupling reactions of multiple halogenated nitrogen-, oxygen-, and sulfur-containing heterocycles. Tetrahedron 2005, 61, 2245-2267. [CrossRef]

54. Fairlamb, I.J.S. Regioselective (site-selective) functionalisation of unsaturated halogenated nitrogen, oxygen and sulfur heterocycles by Pd-catalysed cross-couplings and direct arylation processes. Chem. Soc. Rev. 2007, 36, 1036-1045. [CrossRef] [PubMed]

55. Handy, S.T.; Zhang, Y. A simple guide for predicting regioselectivity in the coupling of polyhaloheteroaromatics. Chem. Commun. 2006, 3, 299-301. [CrossRef] [PubMed]

56. Iaroshenko, V.O.; Gevorgyan, A.; Mkrtchyan, S.; Arakelyan, K.; Grigoryan, T.; Yedoyan, J.; Villinger, A.; Langer, P. Transition-metal-catalyzed arylation of nitroimidazoles and further transformations of manipulable nitro group. J. Org. Chem. 2015, 80, 2103-2119. [CrossRef] [PubMed] 
57. Revesz, L.; Bonne, F.; Makavou, P. Vicinal bromostannanes as novel building blocks for the preparation of diand trisubstituted imidazoles. Tetrahedron Lett. 1998, 39, 5171-5174. [CrossRef]

58. Revesz, L.; Di Padova, F.E.; Buhl, T.; Feifel, R.; Gram, H.; Hiestand, P.; Manning, U.; Wolf, R.; Zimmerlin, A.G. SAR of 2,6-diamino-3,5-difluoropyridinyl substituted heterocycles as novel p38 MAP kinase inhibitors. Bioorg. Med. Chem. Lett. 2002, 12, 2109-2112. [CrossRef]

59. Neildé, K.; Crozet, M.; Terme, T.; Vanelle, P. Synthesis of 4-alkynyl-1,2-dimethyl-5-nitro-1H-imidazoles via microwave-assisted sonogashira cross-coupling reactions. Synthesis 2013, 45, 1349-1356. [CrossRef]

60. Zink, L.; Crozet, M.D.; Terme, T.; Vanelle, P. Long distance- $S_{\mathrm{RN}} 1$ in nitroimidazole series favored by temperature. Tetrahedron Lett. 2011, 52, 6991-6996. [CrossRef]

61. Pedada, S.R.; Satam, V.S.; Tambade, P.J.; Kandadai, S.A.; Hindupur, R.M.; Pati, H.N.; Launay, D.; Martin, D. An Improved Kilogram-scale synthesis of 2-Bromo-4-nitro-1H-imidazole: A key building block of nitroimidazole Drugs. Org. Process Res. Dev. 2013, 17, 1149-1155. [CrossRef]

62. European Committee on Antimicrobial Susceptibility Testing, Version 7.1. 2017. Available online: Http: / / eucast.org (accessed on 16 June 2017).

63. Prieto, P.; Cole, T.; Curren, R.; Gibson, R.M.; Liebsch, M.; Raabe, H.; Tuomainen, A.M.; Whelan, M.; Kinsner-Ovaskainen, A. Assessment of the predictive capacity of the 3T3 Neutral Red Uptake cytotoxicity test method to identify substances not classified for acute oral toxicity (LD50 $>2000 \mathrm{mg} / \mathrm{kg}$ ): Results of an ECVAM validation study. Regul. Toxicol. Pharmacol. 2013, 65, 344-365. [CrossRef] [PubMed]

Sample Availability: Samples of the compounds $\mathbf{3 a}-\mathbf{i}, \mathbf{5}, \mathbf{6}, \mathbf{6} \mathbf{a}-\mathbf{j}, \mathbf{7}, \mathbf{8} \mathbf{a}-\mathbf{j}$ and $\mathbf{9}$ are available from the authors. 